\title{
Associativismo e Certificação na Cafeicultura Mineira: um estudo do Café do Cerrado e do Café da Mantiqueira de Minas $^{1}$
}

\author{
Bruno Benzaquen Perosa² \\ Clésio Marcelino de Jesus ${ }^{3}$ \\ Antonio César Ortega ${ }^{4}$
}

\begin{abstract}
Resumo:
Cada vez mais, o acesso aos principais mercados agroalimentares se mostra condicionado a obtenção de certificações que garantam a presença de atributos de qualidade. No mercado do café, esse processo vem ocorrendo de forma rápida, sendo necessária a organização dos produtores por meio de associações e cooperativas de forma a viabilizar a comercialização da produção em mercados mais diferenciados. O presente estudo analisa o processo de organização de produtores para o estabelecimento de certificações geográficas, as chamadas Indicações Geográficas. Por meio de coleta de dados primários e secundários, foram analisados dois casos no estado de Minas Gerais, o Café do Cerrado e o Café da Mantiqueira de Minas. Considerou-se a história da cafeicultura nessas regiões bem como o perfil dos produtores e das associações que capitanearam a obtenção das IGs. Conclui-se que em ambas as iniciativas, as associações tiveram um papel central no processo de certificação. Ademais, verificou-se que as certificações geográficas complementam outras certificações, mais ligadas a qualidade e sustentabilidade da produção, de forma a agregar maior valor e permitir acesso a mercados de nicho no exterior. Por fim, conclui-se que apesar das iniciativas de IG serem bem-sucedidas em abrir novos mercados, observa-se pouca relação dos atores dessa cadeia produtiva com outros setores locais na busca da formação de uma identidade territorial, como se observa em iniciativas semelhantes na Europa.
\end{abstract}

Palavras-Chave: cafeicultura; cooperativas; certificação; identidade geográfica.

1 Os autores agradecem ao Os autores agradecem ao CNPQ (Projeto 408128/2013-5) e FAPEMIG (APQ-00132-14) pelo apoio a pesquisa que resultou nesse trabalho.

2 Professor Adjunto e pesquisador do Núcleo de Estudos Rurais (NERU) do Instituto de Economia da Universidade Federal de Uberlândia (UFU).E-mail: brunoperosa@ie.ufu.b

3 Professor Adjunto e pesquisador do Núcleo de Estudos Rurais (NERU) do Instituto de Economia da Universidade Federal de Uberlândia (UFU).E-mail: clesiomj@ufu.br

4 Professor Titular, professor permanente do Programa de Pós-graduação em Economia e pesquisador do Núcleo de Estudos Rurais (NERU) do Instituto de Economia da Universidade Federal de Uberlândia (UFU). E-mail: acortega@ufu.br 


\title{
Collective Organization and Certification in Minas Gerais Coffee Production: a case study of Café do Cerrado and Café da Mantiqueira de Minas
}

\begin{abstract}
Quality certification plays a central role in agrifood trade, becoming a requirement to access some markets. In the coffee market, certification are gaining importance, demanding collective organization by farmers in order to achieve the requirements of the main certifications demanded in the most valued markets. This research considers this process of organization among coffee producers to obtain geographic certifications (geographical indication - GI). By collection primary and secondary data, this paper analyzed two of the most important coffee production regions on Minas Gerais State: Café do Cerrado e Café da Mantiqueira de Minas. It was considered the historic precedents of coffee production in each region, exploring the farmers' profile and the association and cooperatives constitution in each region, considering its role in organizing the GI certification. Comparing the two cases, it was possible to conclude that in both cases cooperatives play a central role in the approving the GI certification, and maintaining the certification management. Furthermore, the analysis showed that GI certification has a complementary relation with other certifications, more related to quality and sustainability, and together they allow access to more rewarding markets abroad. Finally, this paper concluded that despite GI initiatives are effective in granting market access, it has not improved the relation among local actors in a way to strength a territorial identity, as observed in similar activities in Europe.
\end{abstract}

Keywords: coffee production; cooperatives; certification; geographic identity.

\section{Classificação JEL: Q13; Q17.}

\section{Introdução}

O Brasil sempre teve uma posição de destaque no mercado internacional de café e, hoje, ocupa a posição de maior exportador mundial. Apesar disso, a cadeia produtiva brasileira encontra grande dificuldade em se firmar como um fornecedor de café de qualidade no mercado internacional (SAES, 2009; SAES e FARINA, 1999).

O acesso aos chamados "mercados premium" está condicionado não só à obtenção de boa qualidade na bebida, mas também ao cumprimento de uma série de requisitos na produção e comercialização desse produto. As certificações são o principal mecanismo de comprovação desses requerimentos, sendo assim fundamental para exportar a produção (LEME, 2015).

Essa dificuldade em produzir um produto de maior qualidade e atingir os requisitos adicionais demandados internacionalmente pode ser explicada, em grande parte, por problemas de coordenação na cadeia produtiva, especialmente no elo 
agrícola (SAES e FARINA, 1999). O longo período de regulação estatal a que essa cadeia esteve submetida, e a brusca interrupção no início dos anos 1990, dificultou a formação de mecanismos de coordenação e comprometeu a adoção de ações que favorecessem o acesso aos novos mercados internacionais. Ao se comparar o Brasil com outros países produtores, como a Colômbia por exemplo, fica evidente a deficiente articulação entre os elos e a dificuldade da produção e exportação de um grão com qualidade superior, na qual permite maior agregação de valor no produto (SAES e FARINA, 1999). A existência de políticas públicas, visando a organização dos produtores, é apontada como um importante diferencial dos colombianos em relação ao Brasil (ORMOND et al., 1999).

A partir de meados dos anos 1990, muitos produtores passaram a se organizar por meio de cooperativas e associações, sendo o caso do Café do Cerrado um dos melhores exemplos nesse sentido. Constitui-se ali uma sólida experiência protagonizada por organizações representativas dos produtos de caráter especializado (ORTEGA, 2005).

As cooperativas de produtores também desempenharam um papel importante nesse processo, pois, se num primeiro momento buscavam somente auxiliar produtores em questões produtivas e comerciais, posteriormente passaram a incentivar ações de caráter políticos organizacionais visando o acesso aos novos mercados (BARRA et. al 2007; SAES; JAYO e SILVEIRA, 1997).

É nesse contexto que começam a surgir as primeiras iniciativas de busca por certificações de indicação geográfica (IG) em território brasileiro, sejam elas na modalidade Denominação de Origem (DO) ou Indicação Geográfica de Procedência (IP). Tanto as organizações representativas como as cooperativas tiveram um papel central na busca de reconhecimento por atributos geográficos dos produtos e, também, na coordenação da conquista de certificação nos territórios produtores, para que seus projetos fossem aprovados junto ao Instituto Nacional de Propriedade Intelectual (INPI).

Apesar das diferenças observadas entre as regiões que buscaram a IG, observa-se que aquelas que conseguiram aprovar seus pedidos têm em comum a existência de associações e cooperativas representativas junto às suas bases sociais. Assim, há que se reconhecer a importância de uma articulada coordenação dos produtores por meio de organizações representativas de caráter político e da ação econômica de suas cooperativas 5 .

Nesse sentido, o objetivo do presente trabalho foi analisar o papel de cooperativas e organizações representativas no processo de obtenção e gestão de IGs, em regiões produtoras de café de qualidade em MG. Bem como analisar de que maneira

5 Ortega (2003) diferencia as organizações representativas de caráter político, daquelas de caráter econômico, como são as cooperativas. Entretanto, chama a atenção que essa tipologia caracteriza tipos ideais, e que dificilmente são encontradas de maneira pura na realidade. Assim, é comum encontrar cooperativas (organizações de caráter econômico) realizando atividades de representação de caráter politico. 
essas iniciativas vêm contribuindo para a construção de uma identidade territorial que potencialize a dinâmica econômica dessas regiões.

De maneira a apresentar evidências empíricas desse processo, foram estudados dois casos de territórios produtores de café em Minas Gerais que obtiveram certificação de indicação geográfica de sua produção: Café do Cerrado, com a conquista da certificação na modalidade Denominação de Origem (DO) e Café Mantiqueira de Minas com a certificação na modalidade Indicação de Procedência (IP). A comparação dessas iniciativas permite explorar qual a estratégia utilizada por cada uma delas para essas conquistas e, também, os ganhos que elas representam para os produtores associados. Tal como buscou-se analisar o perfil dos produtores e das associações que capitanearam as iniciativas de certificação.

A metodologia adotada pela pesquisa está apoiada em informações qualitativas, coletadas por meio de entrevistas em profundidade junto aos produtores e atores chave que atuam nas organizações representativas e cooperativas. Alguns dados socioeconômicos foram obtidos e sistematizados a partir da base de dados do IBGE (Pesquisa Agrícola Municipal-PAM e Pesquisa Pecuária Municipal-PPM). Nossos referenciais teóricos, ainda que não estejam sintetizados aqui em uma seção, são aportes de uso do enfoque territorial e do neo-institucionalismo, particularmente do neocorporativismo, que orienta estudos de representação de interesses. Por sua vez, foi necessária uma revisão em relação às certificações e indicação geográfica, o que também foi feito tomando como referência o neo-institucionalismo, que permitiu análises mais rigorosas dos estudos de casos realizados.

A estrutura deste artigo está dividida em quatro seções, além da introdução. $\mathrm{Na}$ segunda parte será apresentada uma discussão de conceitos teóricos acerca das implicações e dificuldades para a obtenção e gestão de IGs. A seguir, nas seções 3 e 4, serão apresentados os estudos de casos dos territórios do Cerrado Mineiro e da Mantiqueira de Minas. Por fim, são apresentadas as considerações finais e as referências bibliográficas.

\section{O papel das Indicações Geográficas (IGs)}

As Indicações Geográficas (IG) não podem ser consideradas como um mecanismo de certificação em si, mas sim como uma ferramenta para a diferenciação/ singularização de produtos. De acordo com Nierdele (2014: p.1), a IG é um “... direito de propriedade intelectual que reconhece um bem a partir do seu vínculo especifico com um território, que lhe confere identidade e distinção. ”

Para Hoff, Jesus e Ortega (2015), a diferenciação de produtos é uma forma de garantir o reconhecimento de características intrínsecas e extrínsecas, e a conquista de uma IG aliada às certificações de base territorial confere aos produtos agropecuários certa singularidade que lhes possibilitam maior competitividade. A busca da singularização, por meio da construção de uma marca referenciada ao território, permite superar o caráter comoditizado dos produtos primários (ALCOFARADO, 2002).

Nierdele (2014) estabelece três pontos fundamentais para analisar o surgi- 
mento e evolução das IGs: a) melhoria da performance técnica da produção; b) agregação de valor aos produtos e acesso ao mercado; c) preservação do patrimônio cultural e natural. Com relação às mudanças na performance técnica, estudos revelam que o estabelecimento de uma IG busca uma modernização e padronização das técnicas produtivas, o que pode trazer maior competitividade aos produtores que dela se beneficiam. Contudo, ressalte-se, também, que a padronização pode inibir a adoção de novas técnicas mais eficientes e, assim, gerar um impacto negativo sobre a evolução da produtividade dos produtores.

A busca de uma IG visa, portanto, conferir marca a um produto, referenciando-o a um território. Dessa maneira, o que se conquista é a diferenciação de produto e, fazendo isso, busca-se um prêmio adicional ao preço do produto que está identificado com uma IG. Apesar de que não existe nenhuma garantia de preços maiores, e sua obtenção ou acesso aos mercados mais exigentes e melhor remuneradores, dependerá do reconhecimento da singularidade e qualidade que o produto vinculado a uma região obtiver junto aos consumidores.

Por fim, o estabelecimento das IGs visa a preservação do patrimônio cultural e material da região considerada. Nesse sentido, a IG serviria como um instrumento para defender as tradições e características geofísicas e culturais de uma região. Segundo Nierdele (2014, p. 37), seria uma "valorização dos recursos materiais e simbólicos dos territórios (paisagem, saber-fazer coletivo, tradições e costumes locais)". Dessa maneira, ao relacionar um produto às características de uma região, além de se buscar agregar valor ao produto, também é possível proteger um patrimônio imaterial atrelado à região.

Mas seria necessário ter um produto como marca de uma região para estabelecer essa dinâmica? Segundo Nierdele (2014), a existência de um produto e de uma indústria a ele relacionado ajuda a aglutinar os atores em torno de uma proposta de desenvolvimento territorial. $\mathrm{E}$, assim, conferir valor econômico às características imateriais de uma região, o que permitiria uma proteção mais efetiva e sustentável ao longo do tempo.

Neste contexto, a busca por uma indicação geográfica também pode se constituir em uma estratégia para a promoção do desenvolvimento rural, pois incorpora uma série de elementos como cooperação entre os atores locais; proteção e adoção de estratégias comuns para inserção em mercados competitivos; valorização do produtor rural; aumento da produtividade, agregação de valor e renda aos produtores rurais; incrementos na qualidade da produção; divulgação do território; construção de uma identidade territorial; melhor articulação entre produtores rurais e outros segmentos representativos, entre outros elementos (MASCARENHAS, 2008; SOARES, 2012; ORTEGA e JESUS, 2012).

No entanto, em face do elevado grau de exigência, as certificações que podem ser acedidas pelos cafeicultores do Cerrado Mineiro ainda podem ser caracterizadas como excludente, particularmente, para os agricultores familiares. Apesar de todos se beneficiarem da delimitação territorial por meio de uma indicação geográfica. 
Contudo, a construção dessa dinâmica virtuosa entre um produto e as tradições regionais demanda a coordenação dos interesses econômicos individuais com uma estratégia de desenvolvimento territorial. Do ponto de vista empresarial, a agregação de valor está no centro da estratégia de obtenção de IG. Porém, nem sempre as medidas adotadas para obter a maior agregação de valor estão alinhadas com a defesa do patrimônio imaterial ou com o desenvolvimento territorial.

Um exemplo interessante disso está ligado, por exemplo, ao alinhamento das práticas produtivas de forma a atender legislações ou certificações que permitam acesso aos mercados que remuneram melhor pelo produto. Nem sempre o saber-fazer local cumpre esses critérios, o que poderia reduzir o potencial de agregação de valor do produto. Nesse sentido, a IG constituiria uma barreira ao acesso dos produtores a alguns mercados.

Outro elemento de complexa coordenação se refere à propriedade da IG e os critérios para sua utilização no território. A obtenção da IG, em determinados processos produtivos, não implica em critérios de qualidade dos produtos a ela associados. Contudo, a IG pode se constituir em uma importante ferramenta de marketing, desde que essa "marca" esteja restrita aos produtos que se qualifiquem dentro de certos critérios de qualidade. Para isso, é necessário estabelecer critérios para excluir produtores que, apesar de fazerem parte da região e seguirem as técnicas produtivas locais, não produzem um produto de qualidade elevada. Nesse sentido, questiona-se a "propriedade" da IG e qual o direito de excluir outros atores que poderiam comprometer a "marca" atrelada àquela região.

No caso da cafeicultura, esse elemento se revela claramente. Diversas regiões que obtiveram IG, como o Cerrado Mineiro e a Mantiqueira de Minas, estabelecem notas mínimas de qualidade do café seguindo uma escala norte-americana. Dessa forma, os atores que coordenam esperam relacionar a região a um produto de qualidade superior e, assim, potencializar a agregação de valor para os produtores associados. Produtores que não atingirem essas notas não poderão utilizar a IG, mesmo que façam parte da região e sigam as mesmas técnicas produtivas. Por outro lado, há que se reconhecer que fazer parte do território de uma IG pode gerar externalidades positivas, mesmo não participando das regras, como é o caso do reconhecimento dos consumidores de que naquela região se produz um café de qualidade.

Retornando ao argumento inicial de que a IG é, em última instância, um direito de propriedade, cabe uma discussão sobre quem teria sua propriedade e como poderia fazer uso deste. E, no caso de agregação de valor, quem teria direito a se apropriar desse valor. A grande maioria das experiências brasileiras de IG revelam que estas foram obtidas e são coordenadas por agentes privados, como a Associação dos Produtores Artesanais de Cachaça de Salinas (APACS), com a marca "Cachaça da Região de Salinas", ou a Federação dos Cafeicultores com a marca "Café do Cerrado". Esses são agentes que estabeleceram critérios por meio de espaços de governança constituídos para essa finalidade.

6 Para conhecer o papel da APACS na gestão da marca, consultar Jesus, Ortega e Perosa (2016). 


\section{Estudo de caso 1: Território do Café do Cerrado (TCC)}

A presente seção está subdividida em quatro subseções. Na primeira são apresentadas características da produção de café no território Café do Cerrado. A seguir, é analisada a história da organização dos produtores que culminou na obtenção da Indicação Geográfica. O item três trata da gestão da certificação e, o último item, apresenta outras modalidades de certificação presentes na região.

\subsection{A produção do café do cerrado mineiro}

A região do Cerrado Mineiro7, que produz o Café da Região do Cerrado Mineiro, é constituída por 55 municípios no oeste do estado de Minas Gerais ${ }^{8}$, nas microrregiões geográficas do IBGE de Paracatu, Pirapora, Uberlândia, Patrocínio, Patos de Minas, Uberaba, Araxá e Piumhi. Cuja concentração produtiva ocorre em municípios das microrregiões de Uberlândia, Patrocínio e Patos de Minas.

No Cerrado Mineiro, o café encontrou condições bastante favoráveis para seu cultivo. A região possui temperatura média de $18^{\circ} \mathrm{C}$ a $23^{\circ} \mathrm{C}$, altitude de produção cafeeira de 800 a 1.300 metros acima do nível do mar e um índice pluviométrico médio de 1600 milímetros anuais, com baixa umidade relativa do ar no período da colheita. Somadas às características do relevo, essas são condições bastante favoráveis ao cultivo do café. Não por acaso os 176.958 hectares de café plantados naquela área, e distribuídos por 55 municípios, obtiveram uma produção superior a 5,7 milhões sacas de $60 \mathrm{Kg}$, segundo a PAM - IBGE (2013). Analisando as safras de 2013 e 2014 (pelo caráter bianual da produção de café), é possível concluir que esta constitui a maior produtividade média no Cerrado Mineiro em relação ao restante do estado de MG. Nesse território está concentrado cerca de $17 \%$ da área plantada e $23 \%$ da produção do estado, com uma produtividade média de 32 sacas por hectares, enquanto a média estadual foi de 25 sacas em 2013.

A tabela 1 apresenta a área colhida das principais culturas agrícolas (área de pastagens utilizadas para pecuária não foram consideradas) e do café em alguns dos

\footnotetext{
É importante esclarecer que a abrangência das terras de Cerrado em Minas Gerais é muito maior do que as que se concentram nessas microrregiões. O uso da expressão "Cerrado Mineiro", nesse sentido, está ligado ao fato de que é nessas microrregiões que se concentra a produção de café em terras de cerrado no estado mineiro, denominado Café da Região do Cerrado Mineiro.

8 Os 55 municípios produtores de café que, por meio de nove associações, formam o Conselho das Associações de Cafeicultores do Cerrado (Caccer). Estes municípios são: Abadia dos Dourados, Araguari, Arapuá, Araxá, Bambuí, Bonfinópolis, Buritis, Buritizeiro, Campos Altos, Canápolis, Carmo do Paranaíba, Cascalho Rico, Conquista, Coromandel, Córrego Danta, Cruzeiro da Fortaleza, Douradoquara, Estrela do Sul, Grupiara, Guarda Mor, Guimarânia, Ibiá, Indianopolis, Iraí de Minas, João Pinheiro, Lagamar, Lagoa Formosa, Matutina, Medeiros, Monte Alegre, Monte Carmelo, Nova Ponte, Paracatu, Patos de Minas, Patrocínio, Pedrinópolis, Perdizes, Pratinha, Presidente Olegário, Rio Paranaíba, Romaria, Sacramento, Santa Juliana, Santa Rosa da Serra, São Gonçalo do Abaeté, São Gotardo, Serra do Salitre, Tapira, Tiros, Tupaciguara, Uberaba, Uberlândia, Unaí, Varjão de Minas e Vazante.
} 
municípios do TCC. Devido ao grande número de municípios que compõem esse território (55), foram selecionados os 10 com maior área colhida de café. Patrocínio lidera com mais de 31 mil hectares colhidos de café, o que corresponde a mais de $50 \%$ do total da área agrícola desse município. Ao se considerar a proporção de café na área agrícola total de cada município, fica evidente que os principais municípios produtores apresentam uma média muito superior a de MG e do Brasil. Contudo, a média de proporção da área colhida de café no Território do Café do Cerrado é baixa, o que pode ser explicada pela presença de diversos municípios que praticamente não produzem café nesse território. A área agrícola extremamente grande desse território, aliada à diversidade produtiva, também ajudam a explicar esse resultado, no qual coexistem municípios que têm pouca vocação para a cafeicultura (alguns municípios nem apresentam produção cafeeira, segundo os dados coletados).

Tabela 1. Área Colhida Total e do Café no Território do Café do Cerrado (TCC) em 2013

\begin{tabular}{|c|c|c|c|c|c|}
\hline \multicolumn{6}{|c|}{ Area Colhida (ha) } \\
\hline $\begin{array}{l}\text { Municípios Terrítório } \\
\text { do Café do Cerrado }\end{array}$ & $\begin{array}{c}\text { Lavouras } \\
\text { Temporarias } \\
\text { (a) }\end{array}$ & $\begin{array}{c}\text { Lavouras } \\
\text { Permanentes } \\
\text { (b) }\end{array}$ & $\begin{array}{c}\text { Lavouras } \\
\text { Temporárias }+ \\
\text { Permanentes } \\
(a+b)\end{array}$ & Café (c) & $\begin{array}{c}\% \text { Café na } \\
\text { Area Total } \\
c /(a+b)\end{array}$ \\
\hline Patrocínio & 29.210 & 31.555 & 60.765 & 31.182 & $51 \%$ \\
\hline Monte Carmelo & 24.432 & 13.020 & 37.452 & 12.700 & $34 \%$ \\
\hline Serra do Salitre & 11.191 & 12.532 & 23.723 & 12.477 & $53 \%$ \\
\hline Araguari & 44.391 & 11.973 & 56.364 & 11.413 & $20 \%$ \\
\hline Campos Altos & 11.190 & 10.116 & 21.306 & 10.100 & $47 \%$ \\
\hline Rio Paranaíba & 32.095 & 10.465 & 42.560 & 10.000 & $23 \%$ \\
\hline Carmo do Paranaíba & 4.400 & 10.169 & 14.569 & 9.975 & $68 \%$ \\
\hline Coromandel & 76.405 & 8.566 & 84.971 & 8.376 & $10 \%$ \\
\hline Perdizes & 93.005 & 8.343 & 101.348 & 8.300 & $8 \%$ \\
\hline Patos de Minas & 24.706 & 6.419 & 31.125 & 6.308 & $20 \%$ \\
\hline TCC & 1.988 .809 & 190.565 & 2.179 .374 & 176.958 & $8 \%$ \\
\hline Minas Gerais & 4.028 .112 & 1.162 .878 & 5.190 .990 & 1.038 .669 & $20 \%$ \\
\hline Brasil & 65.396 .271 & 5.898 .108 & 71.294 .379 & 2.085 .522 & $3 \%$ \\
\hline
\end{tabular}

Fonte: Elaboração própria a partir de dados da PAM/IBGE.

Já a tabela 2 apresenta a representatividade do valor da produção de café em comparação ao valor do total da produção agrícola (aqui considerando a produção pecuária). Da mesma forma, foram selecionados os 10 municípios com maior valor de produção de café. Patrocínio, novamente, lidera o ranking com o valor da produção de café gerando mais de R 244 milhões e respondendo por mais de 50\% do valor total da produção agropecuária do município. Também é possível notar como o valor da produção cafeeira representa grande parte da produção agropecuária nos 
principais municípios, geralmente ficando acima dos $20 \%$, próximo da média mineira de $21 \%$ e bem acima da média nacional de $4,69 \%$.

Tabela 2. Valor da produção agropecuária e do café no Território do Café do Cerrado (TCC) em 2013

\begin{tabular}{|c|c|c|c|c|c|c|}
\hline \multirow{2}{*}{$\begin{array}{l}\text { Municípios } \\
\text { Território do } \\
\text { Café do Cer- } \\
\text { rado }\end{array}$} & \multicolumn{4}{|c|}{ V. Produção (1.000 R\$) } & \multicolumn{2}{|c|}{ Café } \\
\hline & $\begin{array}{l}\text { Lavouras } \\
\text { Temporárias }\end{array}$ & $\begin{array}{c}\text { Lavouras } \\
\text { permanentes }\end{array}$ & $\begin{array}{l}\text { Produção } \\
\text { Pecuária }\end{array}$ & Total & $\begin{array}{l}\text { V. Produção } \\
\text { (1.000 R\$) }\end{array}$ & $\begin{array}{c}\text { \% no V. } \\
\text { Total }\end{array}$ \\
\hline Patrocínio & 121.516 & 248.497 & 112.466 & 482.479 & 244.119 & 50,60 \\
\hline Monte Carmelo & 97.006 & 117.595 & 36.197 & 250.798 & 111.614 & 44,50 \\
\hline Araguari & 200.717 & 121.287 & 28.095 & 350.099 & 107.648 & 30,75 \\
\hline Serra do Salitre & 33.723 & 101.663 & 39.152 & 174.538 & 101.169 & 57,96 \\
\hline $\begin{array}{c}\text { Carmo do Para- } \\
\text { naíba }\end{array}$ & 18.536 & 92.483 & 67.991 & 179.010 & 90.302 & 50,45 \\
\hline Rio Paranaíba & 294.696 & 93.037 & 54.953 & 442.686 & 84.870 & 19,17 \\
\hline Campos Altos & 74.725 & 80.970 & 11.151 & 166.846 & 80.329 & 48,15 \\
\hline Coromandel & 231.622 & 79.810 & 120.133 & 431.565 & 78.786 & 18,26 \\
\hline Patos de Minas & 115.191 & 77.285 & 166.996 & 359.472 & 75.000 & 20,86 \\
\hline Perdizes & 573.353 & 61.067 & 79.519 & 713.939 & 60.338 & 8,45 \\
\hline TCC & 7.740 .691 & 1.789 .736 & 2.237 .104 & 11.967 .531 & 1.598 .764 & 13,36 \\
\hline Minas Gerais & 15.316 .330 & 9.296 .031 & 10.108 .316 & 34.720 .677 & 7.295 .452 & 21,01 \\
\hline Brasil & 196.083 .410 & 36.385 .583 & 41.150 .997 & 273.619 .990 & 12.820 .331 & 4,69 \\
\hline
\end{tabular}

Fonte: Elaboração própria a partir de dados da PAM e PPM/IBGE

Por fim, a tabela 3 apresenta a proporção de estabelecimentos familiares e da área correspondente nos 20 municípios do TCC com maior área cafeeira. Em Patrocínio, principal município produtor, a AF apresenta um valor modesto se analisado o número de estabelecimentos. Esse valor se mantem acima dos 50\% na maior parte dos principais municípios produtores. De modo geral, no território, a participação da Agricultura Familiar é bem inferior a que se observa a nível estadual e nacional, respectivamente, $58,80 \%, 79,28 \%$ e $84,36 \%$. Contudo, ao se considerar a área ocupada pelos estabelecimentos familiares, encontram-se números mais modestos, cuja média territorial é de 18,65\%, inferior a estadual (26,71\%). Por outro lado, é importante observar que no interior do TCC existem grandes variações entre em municípios: em Carmo do Paranaíba, os estabelecimentos familiares ocupam 41,30\% de área, enquanto em Ibiá não chegam a 8\%. Dados revelam grande heterogeneidade na produção de café no Cerrado Mineiro, em que alguns municípios contam com uma produção significativa da agricultura familiar, especialmente aqueles localizados na região do Alto Paranaíba, enquanto em outros estão concentradas as agriculturas patronais. Por essas características, o peso do agricultor familiar no TCC, 
seja no número de estabelecimentos ou na área ocupada, é bem inferior ao estado de Minas Gerais e Brasil.

Tabela 3. Participação da Agricultura Familiar (AF) no Território do Café do Cerrado (TCC) em 2013

\begin{tabular}{|c|c|c|c|}
\hline \multicolumn{4}{|c|}{ Cerrado } \\
\hline $\begin{array}{c}\text { Municípios Território do Café } \\
\text { do Cerrado }\end{array}$ & Àrea Café & $\%$ de Estab da AF & $\%$ área $\mathrm{AF}$ \\
\hline Patrocínio & 31.182 & 61,84 & 29,14 \\
\hline João Pinheiro & 17.000 & 51,19 & 13,28 \\
\hline Monte Carmelo & 12.700 & 56,15 & 26,15 \\
\hline Serra do Salitre & 12.477 & 53,19 & 23,51 \\
\hline Araguari & 11.413 & 57,69 & 17,81 \\
\hline Campos Altos & 10.100 & 61,57 & 28,29 \\
\hline Rio Paranaíba & 10.000 & 78,04 & 36,88 \\
\hline Carmos do Paranaíba & 9.975 & 73,36 & 41,30 \\
\hline Coromandel & 8.376 & 54,34 & 19,85 \\
\hline Perdizes & 8.300 & 45,58 & 19,90 \\
\hline Patos de Minas & 6.308 & 71,26 & 34,43 \\
\hline Romaria & 5.000 & 54,91 & 10,95 \\
\hline Ibiá & 4.200 & 39,69 & 7,76 \\
\hline Presidente Olegário & 3.755 & 64,11 & 27,06 \\
\hline Medeiros & 3.623 & 71,03 & 33,86 \\
\hline Indianópolis & 3.600 & 54,05 & 22,04 \\
\hline Bambuí & 3.400 & 71,97 & 35,72 \\
\hline Unaí & 3.310 & 55,27 & 16,28 \\
\hline Araxá & 2.200 & 34,81 & 14,16 \\
\hline Estrela do Sul & 2.110 & 65,51 & 12,42 \\
\hline TCC & 192.258 & 58,80 & 18,65 \\
\hline Mians Gerais & 1.038 .669 & 79,28 & 26,71 \\
\hline Brasil & 2.085 .522 & 84,36 & 24,01 \\
\hline
\end{tabular}

Fonte: Elaboração própria a partir de dados do Censo Agropecuário e da PAM /IBGE 


\subsection{Associativismo e IG}

A evolução da atividade cafeeira no Cerrado Mineiro recebeu grande estímulo de políticas governamentais, seja nos assentamentos dirigidos do Alto Paranaíba nos anos de 1970, na pesquisa tecnológica, gerando inovações importantes para a produção na região, no financiamento e na regulação do setor. Entretanto, com as políticas liberalizantes dos anos 1990, como a extinção do Instituto Brasileiro do Café (IBC) e a retirada do Brasil dos acordos internacionais, o setor passa por severa crise, agravadas com a entrada de novos países produtores no mercado mundial, possibilitada pelo fim daqueles acordos, que levaram a um aumento da oferta mundial e à queda em seus preços (ORTEGA e JESUS, 2012). Essa nova realidade acabou incentivando a organização e a regulação privada dos cafeicultores do Cerrado Mineiro, com alguns pioneirismos.

Para enfrentar essa nova realidade institucional, estabeleceu-se uma estrutura de governança baseada nos atores privados, visando ocupar as funções antes realizadas pelo Estado. Assim, os cafeicultores do cerrado mineiro construíram uma experiência resultante de uma nova etapa do associativismo rural no Brasil, em que os agricultores se organizam em função do produto no qual se especializaram e da região em que atuam. Essas organizações representativas, de caráter especializado por produto, retiram boa parte do protagonismo da representação de interesses rurais, antes exercido por organizações sindicais de caráter unitário (ORTEGA, 2005).

No cerrado mineiro, as iniciativas de organização dos produtores ganham força com a fundação do Conselho das Associações de Cafeicultores do Cerrado Mineiro (Caccer) em 1992, com o objetivo de valorizar a cafeicultura da região que, posteriormente, em 2010, passou a denominar-se Federação dos Cafeicultores do Cerrado, cuja base social congrega, aproximadamente, 3500 cafeicultores que produzem em 4600 propriedades.

Desde sua fundação, o Caccer assumiu a responsabilidade pela articulação das ações estratégicas de comercialização da produção, por meio de um marketing que se consolidou mediante a construção de uma marca: Café do Cerrado, hoje denominada Café da Região do Cerrado Mineiro. Para tanto, além dessa estratégia comercial, que passou a ser direta, sem intermediários, há de se reconhecer o importante papel desempenhado por aquela organização no assessoramento técnico junto aos seus filiados.

A diferenciação da produção pela origem vem possibilitando um prêmio de preços para os produtores daquele território e, particularmente, para os beneficiados pela conquista do selo de qualidade Café da Região do Cerrado Mineiro. Portanto, essa estratégia vem construindo vantagens competitivas por meio da referência ao território. Mas, para tanto, dos produtores se exige o uso de determinada tecnologia para, assim, incorporar-se a uma estratégia de marketing e comercialização direta que substitui intermediários. À associação cabe, portanto, fornecer respaldo técnico aos produtores (com apoio importante do Sebrae estadual), pautar as ações 
mercadológicas e agir como entidade de representação. Essa ação estratégica exigiu a articulação de associações intermunicipais de cafeicultores e das cooperativas.

A origem do movimento associativo, que levou à experiência inovadora do Caccer, teve seu início em 1986, quando foi fundada a primeira associação de cafeicultores do cerrado, no município de Araguari: a Associação dos Cafeicultores de Araguari (ACA). Posteriormente, ainda na década de 80, foi fundada a Associação de Apoio aos Produtores Rurais da Região de São Gotardo (Assogotardo). Essa associação teve particular importância no desenvolvimento da cafeicultura do Cerrado Mineiro, decorrente da implementação do Programa de Assentamento Dirigido ao Alto Paranaíba (Padap) no início da década de 1970, que atraiu agricultores com experiência na cafeicultura que fugiam das tradicionais zonas produtoras (São Paulo e Paraná), submetidas constantemente a geadas, para promover uma nova ocupação do cerrado?.

No início da década de 1990, proliferaram outras associações por toda a região. Em 1990, foi criada, no município de Patrocínio, a Associação dos Cafeicultores da Região de Patrocínio (Acarpa); em 1991, foram instituídas a Associação dos Cafeicultores da região de Carmo do Paranaíba (Assocafé), a Associação dos Cafeicultores da região de Monte Carmelo (Amoca) e a Associação dos Cafeicultores de Coromandel (Assocoró) ${ }^{10}$. As últimas associações criadas na região foram a Associação dos Cafeicultores de Campos Altos e Região (Accar), em 1993; a Associação dos Cafeicultores do Nordeste Mineiro (Acanor), em 1997; e a Associação dos Cafeicultores de Sacramento (Acasa), em 1998. Tanto a Accar como a Acasa não estão mais filiadas à Federação dos Cafeicultores da Região do Cerrado. Nos anos 2000, foi criada a Associação dos Pequenos Produtores do Cerrado, cuja sede fica em Patrocínio e está filiada à Federação. Recentemente, foi criada a Associação dos Cafeicultores de Patos de Minas e Região.

O mapa da Figura 1 apresenta a localização territorial das associações que congregam os 55 municípios do Cerrado Mineiro em Minas Gerais. Na parte cinza da figura, tem-se o mapa do Brasil, com a localização de Minas Gerais e, sobreposto a esse estado, o território de Café do Cerrado com as instituições que constituem o Caccer. Cada sigla com a respectiva cor representa uma associação ou cooperativa e os municípios pertencentes a ela, ou seja, cada entidade tem atuação regional: ACA (Associação dos Cafeicultores de Araguari), com seis municípios; Acanor (Associação dos Cafeicultores do Noroeste), com nove municípios; Acarpa (Associação dos Cafeicultores de Patrocínio), com seis municípios; Amoca (Associação dos Cafeicultores de Monte Carmelo), com nove municípios; Assocafé (Associação dos Cafeicultores de Carmo do Paranaíba), com nove municípios; Assogotardo (Associação dos Cafeicultores de São Gotardo), com cinco municípios; Capal (Cooperativa Agropecuária de Araxá), com sete municípios e Capeca (Cooperativa Agropecuária de Campos Altos), com seis municípios.

\footnotetext{
9 Para o tema, pode-se consultar Salim (1986), Ribeiro (1985) e Pessoa (1996).

10 A Assocoró passou por uma crise no inicio dos anos 2000 e foi extinta.
} 
FIGURA 1. Localização das associações dos cafeicultores na região do Cerrado Mineiro.

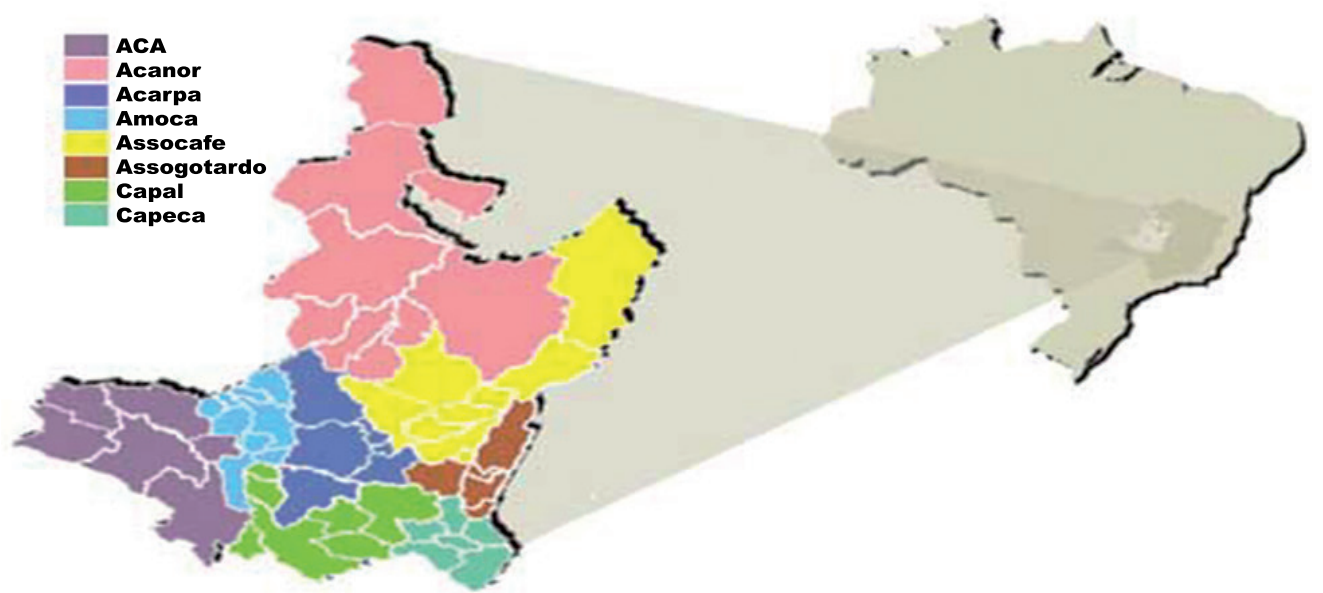

Fonte: Café do Cerrado. Disponível em www.cafedocerrado.org.br

Como resultado dessa organização dos produtores de café no Cerrado Mineiro, o Caccer obteve a demarcação geográfica de sua área de produção e registrou a marca Café do Cerrado para identificar a produção regional. Essa marca, que constituiu a primeira região produtora de café demarcada no Brasil, foi criada pelo governo de Minas Gerais em abril de 1995 e confirmada pelo decreto $481.05 .578 \mathrm{em}$ maio de 1998. Na sequência, também de maneira pioneira na cafeicultura nacional, o Caccer obteve a indicação de procedência reconhecida pelo INPI (Instituto Nacional da Propriedade Industrial). Desde então, cabe ao Caccer atestar a qualidade da produção de seus filiados que atendam às especificações exigidas por aquela certificação, a primeira região de origem produtora de café demarcada no país ${ }^{11}$.

Ainda em 1998, o Caccer foi credenciado pelo governo de Minas Gerais, por intermédio do IMA (Instituto Mineiro de Agropecuária), como certificador de origem e qualidade de café. Ainda naquele ano, outro certificado relevante foi conquistado, junto a SCAA (Associação Americana de Cafés Especiais), a mais importante entidade certificadora desse gênero no mundo, com um consistente e reconhecido sistema de classificação de cafés especiais. E desde 2002, o Caccer vem utilizando a metodologia da SCAA e, assim, com o uso de um sistema de código de barras de logística no certificado, e o selo de garantia costurado na saca de café, permite aos seus compradores verificar a idoneidade do produto, bem como obter maiores informações sobre o sistema de produção utilizado.

11 A marca Café do Cerrado voltou a ser propriedade do Caccer em 2010. A entidade havia perdido os diretos de uso da marca na União Europeia para uma empresa distribuidora da Espanha, que registrou o nome que havia sido contratada pelo Caccer como revendedora. Depois de um ano e meio de negociações, o Caccer pagou 30 mil euros para obter o registro da marca. (http://www. cafedocerrado.org) 


\subsection{A obtenção do IG e a certificação dos cafeicultores no Cerrado}

Um dos principais resultados da organização dos produtores de café no Cerrado Mineiro foi a conquista da demarcação geográfica de sua área que, inicialmente, registrou a marca Café do Cerrado para identificar a produção regional. Em 2011, essa marca foi mudada para adequar melhor à sua localização geográfica e passou a chamar-se Café da Região do Cerrado Mineiro.

A Federação dos Cafeicultores do Cerrado é a gestora e mantenedora da marca e vem estabelecendo convênios com instituições nacionais e internacionais. Esse convênios têm como objetivo criar programas de capacitação para os cafeicultores do Cerrado para atender as exigências de distintas certificações, além da concedida pela própria entidade, que representa oito associações e oito cooperativas filiadas à Federação.

A marca Café do Cerrado foi a primeira do país a ser identificada como região produtora de café demarcada com a indicação geográfica. Ela foi reconhecida, primeiramente, pelo governo de Minas Gerais pelo decreto No 165/95 do IMA, em abril de 1995, que delimitou as regiões produtoras de café do estado de Minas Gerais para a instituição do certificado de origem. Em 1998, de acordo com o Registro $\mathrm{N}^{\mathrm{O}}$ 481.05.478, o Caccer foi credenciado pelo governo de Minas Gerais, por intermédio do IMA, como certificador de origem e qualidade de café, tornando-se a primeira entidade certificadora oficial de café do país. Na sequência, também de maneira pioneira na cafeicultura nacional, o Caccer obteve a indicação de procedência reconhecida pelo INPI (Instituto Nacional da Propriedade Industrial), pelo número: IG 990001 de 14/04/2005, processo que foi depositado em 1999. Com a Indicação de Procedência reconhecida, o passo seguinte foi buscar a Denominação de Origem, processo depositado em 11/11/2010 e conquistado em 31/12/2013, pelo número IG 201011 do INPI (INPI, 2014). Foi necessário provar que seu café é um produto único, que não pode ser obtido em outro local e que há influência social, econômica e cultural da região na sua produção. Mais que utilizar a IG/DO como um instrumento de marketing, sua conquista representa um mecanismo de proteção contra a concorrência por parte de produtos de baixo padrão de qualidade.

Coube ao Caccer e posteriormente à Federação dos Cafeicultores do Cerrado atestar a qualidade da produção de seus filiados que atendam às especificações exigidas por aquela certificação ${ }^{12}$. Para garantir a origem, a qualidade e idoneidade do modelo de produção e de rastreabilidade do produto, o Caccer buscou uma tríade de ações para certificar a propriedade, o produto e o armazém de estocagem/ comercialização. Assim, a Federação possui um sistema de georeferenciamento,

12 A marca Café do Cerrado voltou a ser propriedade do Caccer em 2010. A entidade havia perdido os diretos de uso da marca na União Européia para uma empresa distribuidora da Espanha, que registrou o nome que havia sido contratada pelo Caccer como revendedora. Depois de um ano e meio de negociações, o Caccer pagou 30 mil euros para obter o registro da marca. (http://www. cafedocerrado.org/? $\mathrm{p}=$ noticias\&id=27, 25/set/2010) 
com banco de dados das propriedades certificadas, que permite a localização da propriedade e a precisão de seus limites, a demarcação da área, bem como de reservas legais, altitude, declividade e cursos d'água, além do mapeamento completo das áreas de café.

Os cafeicultores do Cerrado Mineiro, inspirados nas experiências francesa e italiana, certifica o café desde o local onde é plantado até o consumo, de maneira que seus associados recebam um selo de denominação de origem controlada. Os cafeicultores certificados têm de seguir rígidas regras de produção, que proíbem o uso de mão-de-obra infantil, exige o registro em carteira de funcionários, o respeito às normas ambientais, a manutenção de reservas e matas ciliares, além de cuidados especiais no manuseio de produtos tóxicos, com o uso de equipamentos de proteção individual pelos trabalhadores durante as pulverizações ou em outros tratos culturais.

A Federação constitui-se, dessa maneira, no Certificador da Origem reconhecido pela OIC (Organização Internacional do Café), para a região demarcada do Cerrado Mineiro, devidamente credenciado segundo o convênio com o Centro de Comércio de Café de Minas Gerais, representante legal do Cecafé (Conselho dos Exportadores de Café Verde do Brasil). Assim sendo, de acordo com informações da Federação, a emissão do selo da Certificação de Origem Controlada cresceu rapidamente, pois em 2011 foram seladas pouco mais de 30.000 sacas e em 2015 foram seladas mais de 160.000 sacas, e a meta é a de selar cerca de 700.000 sacas em 2020. Cafés destinados, principalmente, ao mercado internacional. Para tanto, a Federação vêm ampliando as propriedades certificadas com a certificação de origem Café da Região do Cerrado Mineiro.

Outra frente que a Federação vem atuando é a de incentivar o consumo nacional por cafés de qualidade, situação que levará a população a demandar cafés com o selo de DO. Para tanto, além de divulgar a marca nacionalmente, a Federação também emite o selo de DO "Café da Região do Cerrado Mineiro" para o café industrializado. Dados de 2015 indicam que foram emitidos mais de 100.000 selos, cuja meta é a de selar mais de 500.000 pacotes de café industrializado em 2020. Para incentivar o consumo de cafés de qualidades e certificados, foi construída uma grande cafeteria em Patrocínio (Sede da Expocaccer) que comercializa o café industrializado localmente e no mercado nacional, além de estabelecer convênios com outras cafeterias no país para que comercializem a marca.

De acordo com os produtores entrevistados, ainda que reconheçam essa importância, o processo de certificação vem avançando lentamente, devido às elevadas exigências para sua obtenção, com a introdução de inovações produtivas de alto custo, como são os casos da irrigação, a mecanização, que exige completa renovação dos cafezais, boa localização (áreas planas) e a modernização da estrutura de secagem. Ademais, aos custos de produção devem ser adicionados os custos com medidas de respeito ao meio ambiente e à legislação trabalhista.

No entanto, essa situação não é motivo para que os produtores que não con- 
seguem conquistar a certificação de sua produção abandonem as organizações as quais são filiados. Eles destacam os benefícios indiretos que a certificação proporciona e que a obtenção da certificação, por parte de outros produtores da região, vem trazendo benefícios para os demais produtores. $\mathrm{Na}$ medida em que os preços pagos pelo café certificado sofreram aumentos, e tem provocado melhoria nos preços pagos a todos, as demais produções do território do café do cerrado recebem o reconhecimento das características geográficas dessa cafeicultura. Portanto, a disseminação da certificação do produto, por meio da marca Café da Região de Cerrado Mineiro, ainda que de maneira restrita, propicia a diferenciação do produto em relação a outras regiões, e vem ocasionando externalidades positivas às propriedades não certificadas da região.

Essas certificações podem ser conferidas à propriedade, ao produto e ao armazém em que a produção fica estocada até a comercialização.

A Certificação de Propriedade, gerenciada pelo Caccer, é baseada no estabelecimento de um Código de Condutas, que exige que os produtores tenham boas práticas agrícolas, responsabilidade social e responsabilidade com o meio-ambiente. A fiscalização da adoção dessas práticas é acompanhada, principalmente, por auditorias externas e pelo mecanismo de rastreabilidade.

O Programa de Certificação do Café do Cerrado, assim como outras certificações que apoiam as ações do território do Café, toma a origem (o território) como referência para sua demarcação. E, em virtude das vantagens obtidas pela produção certificada, há uma expectativa de ampliação do número dos produtores certificados na cafeicultura do Cerrado Mineiro. Essa expectativa se revela na adoção do cumprimento dos itens de verificação realizados por quatro etapas diferentes. Em cada uma dessas etapas, os produtores obtêm estrelas, desde uma até quatro, o que permite o aprendizado e o desenvolvimento gradual por parte do produtor.

O foco declarado por seus implementadores é a obtenção de uma alta qualidade do café verde, para propiciar uma bebida bastante apreciada. Para isso, foi implantado um sistema denominado GIS, sigla em inglês de Sistema de Informações Geográficas, que visualiza as propriedades certificadas por satélite, além de incorporar uma grande quantidade de informações sobre cada talhão (gleba) de café. Essa fiscalização é realizada por empresas terceirizadas que prestam os serviços de consultoria e auditoria, para garantir a idoneidade do sistema Café do Cerrado.

De acordo com os certificadores, os benefícios da certificação são, principalmente: acompanhamento das demandas do mercado nacional e internacional; diferencial de preço, quando aliado à qualidade do café e/ou demanda de mercado; melhor gerenciamento da propriedade; e a harmonia com os aspectos sociais e ambientais.

Os agricultores entrevistados indicaram, por sua vez, as seguintes vantagens na certificação: agregar valor ao produto; ajustar produção às exigências do meio ambiente e aos direitos dos trabalhadores; condições de receber melhores preços; aumentar competitividade; facilitar comercialização; reconhecimento do produto 
nos mercados nacional e internacional; ajustar às exigências (legislações e normas) e as tendências futuras de mercado.

A Certificação de Produto trata-se de uma certificação de Origem e Qualidade do Café da Região do Cerrado Mineiro. É um tipo de certificação que complementa a de propriedade e constitui-se como importante ferramenta de venda para cafés, sendo utilizada pelas Cooperativas do sistema Caccer ${ }^{13}$. A certificação de produto está diretamente ligada à certificação de armazéns credenciados, que também necessitam cumprir uma série de exigências, também ligadas às questões sociais, legislação trabalhista e ambiental, além de seguiram um protocolo para a comercialização do café certificado. Por exemplo, o armazém não pode comercializar um café não certificado como sendo certificado.

Sua norma está registrada no INPI como Regulamento da Região Demarcada do Cerrado Mineiro. Essa certificação tem como fundamento aqueles pertinentes ao conceito de Appèllation, respeitando: a demarcação oficial da região produtora; perfeita caracterização e identificação sensorial da bebida; e possuir normas e condições de produção padronizadas, homogêneas e codificadas, denominadas terroir.

Dessa forma, para a certificação do produto como Café do Cerrado, é necessário o cumprimento dos seguintes requisitos: lote de café sob certificação produzido na região demarcada do Cerrado Mineiro, advindo de uma Fazenda Certificada pelo Caccer hoje Federação; bebida que apresenta as características sensoriais do Café do Cerrado, são cafés pontuados acima de 75 pontos pela metodologia da SCAA - Specialty Coffee Association of America (Associação Americana de Cafés Especiais); lote sob certificação depositado em armazém certificado/credenciado pelo Caccer.

$\mathrm{Na}$ Certificação de Produto, o comprador recebe o Certificado de Origem e Qualidade e o laudo é atestado por um juiz SCAA, que aplica o lacre com código de barras em cada saca de café (cor: verde).

De acordo com o Caccer, os benefícios da Certificação de Produto são, principalmente, os seguintes: lacração na sacaria; informa o nome do produtor, localidade da fazenda, OIC; o controle da qualidade bebida; visualização da pontuação na página Café do Cerrado; rastreabilidade (código de barra no lacre); certificado para cafés 75 pontos acima na metodologia SCAA; diferenciação de preço.

De acordo com o site oficial do Caccer (www.cafedocerrado.org.br):

Ao firmar convênio, em fevereiro de 2003, com a SCAA, maior entidade mundial do gênero, e que introduziu no mercado de cafés a Metodologia de Classificação de Cafés Especiais, o Caccer e suas entidades comerciais passaram a adotar tal metodologia, inclusive para a emissão dos Laudos de Classificação de Café dos lotes sob processo de certificação. Neste caso, o Caccer através de juízes credenciados realiza todos os procedimentos de avaliação técnica dos lotes de café, incluindo-se a emissão do Laudo de Classificação de Café segundo Normas da SCAA para Cafés Especiais.

13 O sistema Caccer, hoje Federação, integra as seguintes cooperativas: Expocaccer e Coopa em Patrocínio; Coocaccer em Araguari, Carmo do Paranaíba e Monte Carmelo; Coagril em Unaí, Capal em Araxá e Copermonte em Monte Carmelo. 
Essa metodologia pontua os cafés de 0 a 100 pontos. São 10 os atributos sensoriais identificados: Fragrância/Aroma; Uniformidade; Xícara Limpa; Doçura; Sabor; Acidez; Corpo; Finalização; Balanço; Conceito Final. Cada um desses atributos recebe 10 pontos.

É importante registrar que a codificação realizada em lotes específicos do produtor acaba promovendo uma diferenciação entre eles. Para muitos, esse é um dos aspectos fundamentais para garantir o sucesso da experiência do Café do Cerrado na busca da qualidade. Essa diferenciação pode ser vista como estímulo para adotar as exigências da certificação, conferindo preços diferenciados. Portanto, adota-se uma prática diferente das de muitas cooperativas, em que é juntada toda a produção e se obtém uma média.

Não se pode deixar de registrar, ainda, que a implementação de uma certificação, como é o caso da Certificação Café de Cerrado, é um processo de construção social, e como tal, está em constate debate, que pode levar a mudanças no protocolo de implementação da certificação, como tem acontecido na experiência do Café da Região do Cerrado. Nesse processo, a Federação vem conduzindo, junto às associações e cooperativas, ajustes nos protocolos para a Certificação Café do Cerrado, sem esquecer que o foco será garantir a origem do café e a sua qualidade de forma ágil com menor burocraticia, para que atraia mais produtores.

\subsection{Outras certificações disponíveis para os cafeicultores do Cerrado Mineiro}

Além de certificação geográfica, os cafeicultores e cooperativas do Cerrado Mineiro têm disponíveis outras certificações, e que também vem sendo utilizadas em conjunto com a certificação Café do Cerrado.

Várias propriedades, quando conquistam um selo de certificação, acabam sendo motivadas a buscarem outras, pois o processo de certificação entre as diferentes certificadoras guarda semelhanças em termos de critérios a serem cumpridos. Ademais, os compradores de café também incentivam essa multicertificação, pois, para a comercialização no mercado externo, diferentes certificações podem abrir novos mercados.

Assim, temos um conjunto amplo de certificações, e, nessa seção, abordar-se-á, ainda que brevemente, aquelas que, de alguma forma, estão presentes no Cerrado Mineiro. Exemplo delas são a UTZ Certified, a Rainforest Alliance Certified, o Fair Trade (Comércio Justo), o Programa Certifica Minas, a Certificação 4C e a certificação BSCA E AAA-NESPRESSO.

Também é relevante ressaltar o importante papel dessas certificações que atuam em conjunto com a certificação regional. Assim, a Federação apoia a adoção de algumas certificações entre seus filiados. Por exemplo, desde 2005, a Expocaccer - cooperativa responsável pela exportação de café do Cerrado Mineiro - passou a ter seus armazéns certificados pela UTZ Certified, uma organização europeia de 
certificação, independente, sem fins lucrativos, criada por compradores e produtores para recompensar as boas práticas no café, assegurando a qualidade social e ambiental na produção de café. O programa Utz Certified oferece segurança para toda a cadeia de café.

Para essa certificação é preciso criar um sistema de rastreabilidade do café ao longo de toda a cadeia, desde o produtor até o torrefador, o que permite aos compradores conhecerem a sua origem e forma de produção. Umas das exigências feitas para obtenção da certificação é a de que seja implementada uma Cadeia de Custódia Utz Certified, que assegura que o produto certificado não seja misturado a um não-certificado.

O programa de certificação Utz Certified é baseado no Código de Conduta que reúne um conjunto de critérios que assegura o uso de práticas responsáveis para o meio ambiente e a sociedade, segurança dos trabalhadores, direitos autorais fundamentados, acesso à saúde, educação e gestão eficiente da propriedade. Os produtores de café certificados devem atender a esse Código de Conduta e são fiscalizados por certificadores independentes, que realizam inspeções anuais para verificar se as exigências vêm sendo atendidas, também chamada de auditorias de certificação. Segundo os dados da Federação, essa certificação atingiu 35.000 hectares de lavoura no Cerrado Mineiro em 2015.

Enquanto isso, outra certificação utilizada por vários cafeicultores do Cerrado Mineiro,, desde meados da primeira década deste século, é a Rainforest Alliance Certified, de origem americana. Essa certificação foi criada como resultado da ação da Rede de Agricultura Sustentável (RAS) ${ }^{14}$, que busca a sustentabilidade social e ambiental da produção agrícola mediante o desenvolvimento de determinadas normas. A RAS desenvolveu o conceito de agricultura sustentável para integrar as necessidades de propriedades, trabalhadores, comunidades rurais, consumidores e meio ambiente, com objetivo de aumentar os benefícios sociais e econômicos de propriedades e também minimizar os impactos ambientais. Ou seja, busca-se promover a agricultura produtiva, com conservação da biodiversidade e desenvolvimento humano sustentável, mediante a criação de normas sociais e ambientais.

A RAS também incentiva a adoção de práticas sustentáveis para a cadeia de valor agropecuária, incentivando os produtores a cumprirem as suas normas, e os comerciantes e consumidores a apoiarem a sustentabilidade.

Adota-se, para tanto, um criterioso sistema de rastreamento do produto, que incluem as operações de produção, processamento, armazenamento, manejo e distribuição de produtos agrícolas certificados. O que exige, por parte das organiza-

14 A Rede de Agricultura Sustentável (RAS) reúne um conjunto de organizações não governamentais visando a conservação da biodiversidade, exigindo ações conservacionistas que promovem a sustentabilidade social e ambiental da produção agrícola mediante o desenvolvimento de normas para a concessão do selo Rainforest Alliance Certified. Sua sede está localizada em New York e possui escritórios espalhados pelo mundo. Para maiores informações ver: http://www.rainforest-alliance. org/. 
ções certificadas, significativos investimentos em consultorias especializadas para a implementação de taxas para empresas conveniadas em auditorias. No mercado nacional existem empresas que prestam esses serviços, e garantem a idoneidade do sistema. Segundo o balanço da própria certificadora, essa foi a certificação que mais avançou nas propriedades de café do Cerrado Mineiro, alcançando 45.000 hectares em 2015.

Em virtude do número crescente de cafeicultores do Cerrado Mineiro que passaram a certificar suas propriedades conforme os requisitos da RAS e fornecerem café com o selo Rainforest Alliance Certified, a Expocaccer teve de estabelecer um conjunto de normas para receber esse café de seus filiados em seus armazéns, o que garantiu o credenciamento para receber café proveniente das propriedades que cumprem o critério da Rede de Agricultura Sustentável.

Além dessas duas certificações privadas mencionadas, o governo do estado de Minas Gerais também desenvolveu um programa de certificação da cafeicultura estadual. Nesse sentido, criou o Programa de Certificação de Propriedades Cafeeiras do Estado de Minas Gerais (Certifica Minas Café), um programa estruturador, com coordenação da SEAPA, EMATER-MG, IMA e EPAMIG. Essa certificação visa garantir a procedência, a qualidade e o modelo de produção, atendendo a legislação brasileira e as exigências dos mercados. Dessa maneira, busca-se aperfeiçoar os produtores e permitir um melhor acesso aos mercados mais exigentes.

Essa certificação visa a melhoraria da qualidade do café produzido no estado, incentivando as propriedades a adotarem boas práticas agrícolas em todos os estágios da produção, atendendo às normas ambientais e trabalhistas, o que garante ao consumidor final um café diferenciado. A Emater-MG, com seus técnicos, presta assistência técnica e orienta os cafeicultores nas etapas produtivas para a adequação das propriedades ao programa de certificação, por meio do diagnóstico que permite orientar a aplicação do código de conduta estabelecido pela certificação. Esse código foi elaborado por especialistas da Emater-MG, Epamig e IMA, e segue os preceitos das principais entidades certificadoras internacionais, adaptado à realidade dos produtores de Minas Gerais ${ }^{15}$.

Assim, o Certifica Minas atesta, por exemplo, que o café não oferece perigo à saúde do consumidor, pois está livre de contaminação física, química e biológica. Ao mesmo tempo, atesta a origem do produto e gera benefícios ao meio ambiente, ao exigir o uso adequado do solo e da água, a reutilização dos resíduos e a destinação de $20 \%$ da propriedade para preservação ambiental, respeitando a obrigatoriedade de área de Reserva Legal na propriedade.

Seguindo tais orientações, o Certifica Minas Café atesta que as propriedades produtoras estão em conformidade com as exigências do comércio mundial, possi-

15 De acordo com informações disponibilizadas no sítio da Emater os produtores precisam registrar todas as atividades ligadas ao processo de produção, dos insumos usados, ao processo de colheita e pós-colheita e investimentos feitos (terreiros para secagem, aquisição de equipamentos etc.). 
bilitando ao café mineiro consolidar e conquistar novos mercados, com expectativa de gerar maior agregação de valor ao café certificado.

Para tanto, enquanto a Emater-MG faz as orientações para adequações das propriedades, o IMA realiza as auditorias preliminares para atestar as adequações de acordo com os padrões internacionais. No fim do processo, uma certificadora de reconhecimento internacional realiza uma auditoria final e concede a certificação às propriedades aprovadas. Em 2015, a estimativa da federação apontou que cerca de 21.000 hectáres do Café do Cerrado contava com o Certifica Minas.

Além disso, não se pode esquecer que vários compradores de café vêm exigindo, dos produtores, a prática da produção e comercialização baseada no Fair Trade (Comércio Justo), especialmente os agricultores familiares. Como é o caso dos cafés comprados pela rede mundial de cafeterias Starbucks.

O movimento Fair Trade tem como base a sustentabilidade econômica e ecológica para o comércio internacional, e procura estabelecer preços justos à cadeia produtiva, desde que sejam atendidos padrões sociais e ambientais em equilíbrio. Assim, o objetivo é seguir um padrão de compra de café baseado em negociar preços justos, engajar-se em relacionamentos de longo prazo, negociar diretamente com os fornecedores e investir em projetos sociais e ambientais.

Segundo Jesus e Perosa (2015), na região do Cerrado mineiro, outra experiência de comércio justo de café que merece destaque é a Associação dos Pequenos Produtores do Cerrado (APPCER). A associação está localizada no município de Patrocínio-MG, o principal município produtor dentre os que compõem o território do Cerrado Mineiro, tendo negociado mais de 12.000 sacas de café na safra de 2015 com o selo Fair Trade. A tendência é que esse volume cresca, pois já foram certificados mais de 1.000 hectares que podem comcercializar na modalidade Fair Trade.

Outra certificação encontrada é a 4C (Código Comum para a Comunidade Cafeeira), com sede na Alemanha, foi criada para facilitar os processos de certificação. Essa certificação tem como objetivo estabelecer baixos custos para sua adoção, em função da simplicidade de seus protocolos. Isso favorece a inclusão de um maior número de cafeicultores, especialmente os pequenos produtores. Como consequência, a certificação $4 \mathrm{C}$ vem sendo adotada em vários países produtores de café espalhados pelo mundo.

Essa certificação busca criar um sistema sustentável com um código de conduta global, que se baseia nas metas do milênio patrocinadas pelas Nações Unidas. Pretende-se, por meio dessa certificação, incentivar a adoção de boas práticas agrícolas e de gestão, visando promover a sustentabilidade social, ambiental e econômica da produção, do processamento pós-colheita e da comercialização do café. Uma iniciativa do setor para promover sustentabilidade na cadeia do café verde. Várias empresas mundiais, grandes importadores e exportadores de café (tradings) vêm adotando a certificação $4 \mathrm{C}$ na compra de sua matéria prima, como é o caso da divisão de café da Nestlé com a marca Nescafé. 
No Brasil, a Associação Brasileira da Indústria de Café (ABIC) vem adotando um conjunto de medidas para melhorar a qualidade do café industrializado, para o mercado interno e externo. Uma das medidas é o incentivo para que as indústrias nacionais de café, dentro da nova tendência mundial, a do consumo consciente, adquiram cafés que sejam produzidos respeitando a sustentabilidade econômica, social e ambiental, por meio do incentivo à compra de cafés certificados com os selos aqui apresentado, inclusive o selo Café do Cerrado.

Como pode-se perceber, a certificação é uma tendência, ainda que seja por imposição das tradings companies comercializadoras de café, ela vem avançando pelas propriedades e armazéns do Cerrado Mineiro. Ressalte-se, entretanto, que esses selos certificam o produto e seu processo de produção, sem gerar necessariamente um diferencial vinculado à região, como é o caso da Certificação Café do Cerrado.

\section{Estudo de caso 2: Território do Café Mantiqueira de Minas (TCM)}

A presente seção também está subdividida em 4 subseções. Na primeira é apresentado um histórico da produção cafeeira na região da Mantiqueira de Minas. A segunda apresenta um panorama atual da agricultura nos 25 municípios que compõem esse território. $\mathrm{Na}$ terceira subseção, são apresentados os resultados das entrevistas em profundidade realizadas junto aos produtores e representantes das associações, de forma a compreender o processo de organização e coordenação dos produtores até obtenção da IG. O item 4.4 discute como a certificação IG vem sendo utilizada em conjunto com outras certificações de forma a permitir o acesso a novos mercados.

\subsection{Histórico do Café no Sul de Minas e Mantiqueira}

A região da Mantiqueira, no estado de Minas Gerais, figura como uma das principais áreas produtoras de café de qualidade no Brasil. As condições topográficas, caracterizada por um relevo montanhoso e com altitude mediana superior a 1000 metros, se mostra propícia para cultivo de diversas variedades de café gourmet.

Historicamente, observa-se que a primeira expansão do café no Sul de Minas remete ao final do século XIX. Apesar de a cultura já estar estabelecida na região desde o séc. XVII, ocupando um espaço deixado pelo declínio da mineração, é somente a partir de 1870 que se observa um processo mais sustentável do desenvolvimento da cafeicultura (CAÇÃ O, 2012).

Existe certa discordância com relação a origem dos produtores da região. Segundo Singer (1968), estes teriam vindo do Vale do Paraíba, no estado de São Paulo. Outros autores, como Lima (1981), argumentam que a cafeicultura teria vindo da zona da mata mineira, que a época respondia por $2 / 3$ da produção de café em Minas Gerais. Essa migração teria ocorrido devido à desorganização da produção nessa região após a abolição da escravidão. Por fim, outros estudiosos, como Filetto (2000), defendem que a cafeicultura teria ingressado na Mantiqueira a partir de distintas áreas da região fronteiriça entre Minas Gerais, São Paulo e Rio de Janeiro. Na região do Vale 
dos Rios Sapucaí, Lourenço, Velho, Verde e Grande, a cafeicultura teria vindo do Rio de Janeiro, enquanto a cafeicultura do Rio Pardo (próximo a Poços de Caldas) vinha de São Paulo (CAÇÃO, 2012).

Quanto às variedades, o Sul de Minas sempre se destacou pelo cultivo de variedades de café arábica, considerado mais nobre do que as variedades robustas. Segundo o estudo de Vilela e Rufino (2012), as duas variedades mais presentes na região são o Mundo Novo e Catuaí Vermelho, presentes em $71 \%$ e $64 \%$ das propriedades, respectivamente. A forma de plantio é feita com pomares adensados, com distância média entre as plantas entre 2,5 e 3,5 metros, podendo variar a depender da variedade escolhida. O adensamento é fundamental para o melhor aproveitamento da área que devido à declividade elevada dificulta o plantio em grandes áreas.

Ademais, a cafeicultura na região se destaca pelo plantio em relevo de montanha, com altitudes entre 900 a 1400 metros. O plantio nessas condições, a chamada cafeicultura de montanha, exige técnicas especiais e apresenta uso restrito de maquinário para colheita.

Um estudo minucioso sobre a cafeicultura de montanha em MG, organizado por Villela e Rufino (2012), expõe as diferenças dessa modalidade em relação à cafeicultura realizada em terreno plano e baixas altitudes. Segundo os autores, geralmente as regiões com terrenos acidentados apresentam maior dificuldade em desenvolver a agricultura, o que geralmente acarreta em níveis de desenvolvimento menores. Ressalta-se, assim, a importância de políticas que permitam uma valorização dos produtos agrícolas, de forma a arcar com os custos mais elevados que o cultivo nessas condições impõe.

Mas é justamente esse relevo que permite a produção de um café de qualidade diferenciada. A produção em montanhas, marcadas pela grande declividade nas áreas de plantio e a elevada altitude, conferem sabor e qualidade à bebida ali produzida.

Contudo, se por um lado essas características conferem qualidade superior ao café da região, elas também elevam substancialmente os custos de produção. Se comparado ao Cerrado Mineiro, os custos na Mantiqueira são até $50 \%$ superiores. Isso se explica pela dificuldade em introduzir práticas mecanizadas de plantio e colheita, necessitando este ser realizado de forma manual.

Como se constatará a seguir, esses elementos estão no cerne das ações dos produtores visando agregar maior valor ao produto. Apesar da característica de montanha conferir ganhos de qualidade ao café, os produtores da região tinham grande dificuldade em obter uma maior remuneração por esse produto. A comoditização do café, que havia se estabelecido no Brasil até o final dos anos 1980, em grande parte devido à própria atuação do Estado via Instituto Brasileiro do Café (IBC), dificultava a diferenciação do produto. Assim, o café produzido nessas condições apresentava uma grande desvantagem, pois seu custo superior não era compensado por preço melhor, mesmo que sua qualidade justificasse um prêmio sobre preços.

É justamente a busca por essa diferenciação, e uma maior rentabilidade, que motiva os produtores da região de Mantiqueira de Minas em buscar, por meio de suas associações e cooperativas, uma estratégia coletiva para diferenciar o café da Mantiqueira. 


\subsection{A produção de Café na Região da Mantiqueira de Minas}

A serra da Mantiqueira abrange uma vasta área entre os estados de Minas Gerais, São Paulo e Rio de Janeiro, se estendendo por mais de $500 \mathrm{~km}$. Minas Gerais abriga a maior parte desse território (60\%), com uma altitude média de 1200 a 2800 metros. A altitude, somada à vegetação tropical, conferem um clima mais ameno à região, a tornando muito propícia para culturas agrícolas como o café.

O território constituído para a obtenção da IG cobre uma área de 25 municípios16, nos quais a atividade agrícola representa parte considerável das economias locais.

Como explicitado acima, a região da Mantiqueira é reconhecida pela produção de café, iniciada desde o século XVII. A presente seção apresenta alguns dados colhidos junto à base de dados SIDRA/IBGE, coletados por meio da Pesquisa Agrícola Municipal (PAM) e da Pesquisa Pecuária Municipal (PPM). OS dados foram coletados para os municípios que compõem a IG Mantiqueira de Minas, visando mostrar a importância do café nessas regiões.

Tabela 4. Área Colhida Total e do Café no Território do Café da Mantiqueira (TCM) em 2013

\begin{tabular}{|c|c|c|c|c|c|}
\hline \multicolumn{6}{|c|}{ Área Colhida (ha) } \\
\hline $\begin{array}{l}\text { Municípios Território } \\
\text { do Café da Mantiqueira }\end{array}$ & $\begin{array}{c}\text { Lavouras } \\
\text { Temporárias } \\
\text { (a) }\end{array}$ & $\begin{array}{c}\text { Lavouras } \\
\text { Permanentes } \\
\text { (b) }\end{array}$ & $\begin{array}{c}\text { Lavouras } \\
\text { Temporárias }+ \\
\text { Permanentes } \\
(a+b) \\
\end{array}$ & Café (c) & $\begin{array}{c}\% \text { Café na } \\
\text { Área Total } \\
c /(a+b)\end{array}$ \\
\hline São Gonçalo do Sapucaí & 5.760 & 7.444 & 13.204 & 7.314 & $55 \%$ \\
\hline Lambari & 813 & 6.259 & 7.072 & 6.177 & $87 \%$ \\
\hline Santa Rita do Sapucaí & 467 & 6.180 & 6.647 & 6.096 & $92 \%$ \\
\hline Cambuquira & 3.469 & 5.622 & 9.091 & 5.400 & $59 \%$ \\
\hline Campanha & 2.736 & 5.713 & 8.449 & 4.575 & $54 \%$ \\
\hline Conceição do Rio Verde & 5.740 & 4.429 & 10.169 & 4.335 & $43 \%$ \\
\hline Carmo de Minas & 1.891 & 4.283 & 6.174 & 4.145 & $67 \%$ \\
\hline Heliodora & 1.040 & 3.454 & 4.494 & 3.445 & $77 \%$ \\
\hline Pedralva & 679 & 4.921 & 5.600 & 3.365 & $60 \%$ \\
\hline Natércia & 910 & 2.380 & 3.290 & 2.000 & $61 \%$ \\
\hline TCM & 35.723 & 68.377 & 104.100 & 59.861 & $58 \%$ \\
\hline Minas Gerais & 4.028 .112 & 1.162 .878 & 5.190 .990 & 1.038 .669 & $20 \%$ \\
\hline Brasil & 65.396 .271 & 5.898 .108 & 71.294 .379 & 2.085 .522 & $3 \%$ \\
\hline
\end{tabular}

Fonte: Elaboração própria a partir de dados da PAM/IBGE

16 Baependi, Brazópolis, Cachoeira de Minas, Cambuquira, Campanha, Carmo de Minas, Caxambu, Conceição das Pedras, Conceição do Rio Verde, Cristina, Dom Viçoso, Heliodora, Jesuânia, Lambari, Natércia, Olipio, Noronha, Paraisópolis, Pedralva, Piranguinho, Pouso Alto, Santa Rita do Sapucaí, São Gonçalo do Sapucaí, São Lourenço, São Sebastião da Bela Vista, Soledade de Minas. 
Observa-se que na grande maioria dos 25 municípios que compõem a região, a cafeicultura é a cultura mais relevante. Em 15 desses municípios, a cafeicultura representa mais de 50\% da área total colhida. Santa Rita do Sapucaí se destaca como o município com a maior proporção de cafezais na área agrícola colhida, atingindo $92 \%$. Carmo de Minas, onde está sediada a principal associação de representação dos produtores de café, e responsável pela gestão da IG, tem $67 \%$ de sua área agrícola ocupada pela cafeicultura.

Quando se olha a área média ocupada pela cafeicultura em todo o território, verifica-se que o café representava $58 \%$ da área colhida no território Café da Mantiqueira. Quando comparado ao Estado de Minas Gerais e ao restante do Brasil, com respectivamente $20 \%$ e $3 \%$ de suas áreas colhidas representadas pela cafeicultura, fica evidente como essa atividade é marcante para os agricultores da região. Esse número evidencia a importância dessa atividade, bem como a identidade que tal região tem com relação à cafeicultura.

Em 2013, os 59.861 hectares de café plantados no território Café da Mantiqueira, distribuídos por 25 municípios, obtiveram produção próxima a 1,4 milhões sacas de $60 \mathrm{Kg}$ (PAM - IBGE 2013). A produtividade da região manteve-se próxima da média estadual, respectivamente, 23 e 24 sacas por hectares.

Ao se comparar a proporção da área destinada à cafeicultura no Território da Mantiqueira com a observada no Território do Cerrado (em torno de 9\%) (tabela 1), fica claro como a definição do primeiro território foi mais pautada por critérios diretamente ligados à produção cafeeira. No Cerrado, foram inseridos diversos municípios sem nenhuma vocação para a cafeicultura.

Quanto ao valor da produção agrícola, novamente a cafeicultura desponta como a principal atividade agrícola. A tabela 5 apresenta o valor da produção agropecuária, bem como o percentual desta que é representado pela cafeicultura. Vale ressaltar que nessa contabilidade, também, foram incluídos os valores da produção pecuária com dados da Pesquisa Pecuária Municipal (PPM), o que tende a reduzir um pouco o peso da cafeicultura sobre o valor total gerado. 
Tabela 5. Valor da produção agropecuária e do café no Território do Café da Mantiqueira (TCM) em 2013

\begin{tabular}{|c|c|c|c|c|c|c|}
\hline \multirow{2}{*}{$\begin{array}{l}\text { Municípios Ter- } \\
\text { ritório do Café } \\
\text { do Cerrado }\end{array}$} & \multicolumn{4}{|c|}{ V. Produção (1.000 R\$) } & \multicolumn{2}{|c|}{ Café } \\
\hline & $\begin{array}{c}\text { Lavouras } \\
\text { Temporárias }\end{array}$ & $\begin{array}{c}\text { Lavouras } \\
\text { permanentes }\end{array}$ & $\begin{array}{l}\text { Produção } \\
\text { Pecuária }\end{array}$ & Total & $\begin{array}{c}\text { V. Produção } \\
\text { (1.000 R\$) }\end{array}$ & $\begin{array}{c}\text { \% no V. } \\
\text { Total }\end{array}$ \\
\hline $\begin{array}{l}\text { São Gonçalo do } \\
\text { Sapucaí }\end{array}$ & $23.722,00$ & $44.025,00$ & $18.402,00$ & $86.149,00$ & $41.472,00$ & 48,14 \\
\hline Santa Rita do Sapucaí & $2.520,00$ & $39.493,00$ & $20.527,00$ & $62.540,00$ & $38.670,00$ & 61,83 \\
\hline Lambari & $2.025,00$ & $38.745,00$ & $4.347,00$ & $45.117,00$ & $37.488,00$ & 83,09 \\
\hline Carmo de Minas & $4.325,00$ & $33.748,00$ & $18.901,00$ & $56.974,00$ & $32.119,00$ & 56,37 \\
\hline Cambuquira & $8.358,00$ & $32.428,00$ & $6.716,00$ & $47.502,00$ & $29.160,00$ & 61,39 \\
\hline Campanha & $7.403,00$ & $41.528,00$ & $3.989,00$ & $52.920,00$ & $27.176,00$ & 51,35 \\
\hline Pedralva & $2.272,00$ & $40.125,00$ & $15.181,00$ & $57.578,00$ & $25.615,00$ & 44,49 \\
\hline Heliodora & $7.019,00$ & $24.962,00$ & $5.995,00$ & $37.976,00$ & $24.837,00$ & 65,40 \\
\hline $\begin{array}{c}\text { Conceição do Rio } \\
\text { Verde } \\
\end{array}$ & $16.824,00$ & $25.744,00$ & $12.192,00$ & $54.760,00$ & $23.378,00$ & 42,69 \\
\hline $\begin{array}{c}\text { Conceição das } \\
\text { Pedras }\end{array}$ & $3.537,00$ & $19.343,00$ & $4.475,00$ & $27.355,00$ & $13.787,00$ & 50,40 \\
\hline TCM & $145.646,00$ & $476.164,00$ & $268.665,00$ & $890.475,00$ & $374.521,00$ & 42,06 \\
\hline Minas Gerais & $15.316 .330,00$ & $9.296 .031,00$ & $10.108 .316,00$ & $34.720 .677,00$ & $7.295 .452,00$ & 21,01 \\
\hline Brasil & $196.083 .410,00$ & $36.385 .583,00$ & $41.150 .997,00$ & $273.619 .990,00$ & $12.820 .331,00$ & 4,69 \\
\hline
\end{tabular}

Fonte: Elaboração própria a partir de dados da PAM e PPM/IBGE

Ainda assim, a cafeicultura representa mais de $50 \%$ do valor da produção agropecuária em, ao menos, 10 municípios. O maior percentual está em Lambari, onde $83 \%$ do valor da produção advêm da cafeicultura. Quando se observa o valor total do território, verifica-se que $42 \%$ é oriundo da atividade cafeeira, muito superior ao valor encontrado no estado de Minas Gerais (21\%) e no Brasil (4,7\%). Assim, os dados referentes ao valor da produção reforçam a importância da cafeicultura que, na grande maioria dos municípios, lidera o ranking de atividade econômica de maior relevância. O valor final da produção é bem inferior ao do Cerrado e mais distribuído entre os municípios.

Por fim, a tabela 6 apresenta o perfil das propriedades rurais na região, considerando o número de estabelecimentos e a área agrícola ocupada pela agricultura familiar. Ao se considerar o número de estabelecimentos, verifica-se uma elevada proporção de estabelecimentos classificados como agricultura familiar ${ }^{17}$. Pirangui-

17 Segundo a Lei $n^{\circ} 11.326$, de 24 de julho de 2006, são classificadas como propriedades familiares aquelas que atenderem a quatro critérios: I - não detenha, a qualquer título, área maior do que 4 (quatro) módulos fiscais;

II - Utilize predominantemente mão de obra da própria família nas atividades econômicas do seu estabelecimento ou empreendimento; III - tenha renda familiar predominantemente originada de 
nho lidera o ranking com relação à maior proporção de propriedades familiares em relação ao número total de propriedades da região. De forma geral, a proporção de unidades familiares é elevada (acima de 50\% na maior parte dos municípios), contudo, esse percentual fica abaixo das médias estaduais e federais. Chama a atenção o município de Carmo de Minas, principal polo de produção cafeeira no território, apresentar uma das menores proporções de estabelecimentos familiares em relação ao total $(43,10 \%)$.

Tabela 6. Participação da Agricultura Familiar (AF) no Território do Café da Mantiqueira (TCM) em 2013

\begin{tabular}{|c|c|c|c|}
\hline $\begin{array}{c}\text { Municípios Território do Café } \\
\text { da Mantiqueira }\end{array}$ & Àrea Café & $\%$ de Estab da AF & $\%$ área $\mathrm{AF}$ \\
\hline São Gonçalo do Sapucaí & 7.314 & 63,93 & 21,79 \\
\hline Lambari & 6.177 & 81,48 & 60,58 \\
\hline Santa Rita do Sapucaí & 6.096 & 64,34 & 17,98 \\
\hline Cambuquira & 5.400 & 59,15 & 20,00 \\
\hline Campanha & 4.575 & 61,43 & 31,38 \\
\hline Conceição do Rio Verde & 4.335 & 54,73 & 29,16 \\
\hline Carmo de Minas & 4.145 & 43,10 & 13,02 \\
\hline Heliodora & 3.445 & 74,03 & 46,99 \\
\hline Pedralva & 3.365 & 83,11 & 46,72 \\
\hline Natércia & 2.000 & 73,85 & 55,62 \\
\hline Conceição de Pedras & 1.811 & 81,58 & 52,07 \\
\hline Jesuânia & 1.570 & 82,09 & 35,04 \\
\hline Baependi & 1.542 & 75,38 & 52,35 \\
\hline Cachoeira de Minas & 1.390 & 72,52 & 51,52 \\
\hline Cristina & 1.295 & 75,70 & 47,01 \\
\hline Brazópolis & 1.220 & 78,41 & 46,87 \\
\hline Olipio Noronha & 1.200 & 41,13 & 29,00 \\
\hline São Sebastião da Bela Vista & 1.050 & 56,73 & 29,39 \\
\hline Piranguinho & 750 & 84,30 & 39,39 \\
\hline Soledade de Minas & 334 & 70,63 & 46,56 \\
\hline TCM & 59.861 & 71,22 & 37,96 \\
\hline Minas Gerais & 1.038 .669 & 79,28 & 26,71 \\
\hline Brasil & 2.085 .522 & 84,36 & 24,01 \\
\hline
\end{tabular}

Fonte: Elaboração própria a partir de dados da PAM e PPM/IBGE

atividades econômicas vinculadas ao próprio estabelecimento ou empreendimento; IV - dirija seu estabelecimento ou empreendimento com sua família. 
Quando se considera a área representada por estabelecimentos familiares, Lambari lidera a lista de municípios com maior proporção de área ocupada por estabelecimentos familiares, sendo estes responsáveis por 60,08\% da área agrícola municipal. Novamente chama a atenção o fato de Carmo de Minas apresentar a menor proporção de área ocupada por estabelecimentos familiares dentre as municipalidades do território, com apenas 13,02\%. Essa relação, entre maiores áreas colhidas de café com a menor proporção de área da agricultura familiar, se estende a vários outros municípios, evidenciando uma relação inversamente proporcional entre a importância do município como produtor de café e perfil familiar dos produtores. São poucos os municípios que fogem dessa regra, como Lambari que, apesar de apresentar a segunda maior área colhida de café (6.177 ha), tem mais de 60\% de sua área cultivada em propriedades familiares. A explicação para esse fato está ligada ao faturamento bruto da atividade cafeeira, que exclui propriedades, mesmo que pequenas, dos critérios de agricultura familiar estabelecidos pelo Ministério do Desenvolvimento Agrário (MDA).

\subsection{Associativismo e IG na Mantiqueira de Minas}

A presente seção está dedicada a analisar a forma como os produtores do território da Mantiqueira de Minas se organizaram para buscar a aprovação da Indicação Geográfica. Além de considerar os atores públicos e privados envolvidos nesse processo, buscou-se entender os critérios estabelecidos para o uso da IG entre os diferentes produtores do território.

Em 1997 foi fundada a Associação dos Produtores de Café da Mantiqueira (APROCAM), congregando cerca de 50 produtores cooperados da Cooperativa Regional dos Cafeicultores do Vale do Rio Verde (COCARIVE). Esse grupo se distinguia por produzir cafés especiais e buscava se organizar para implementar estratégias de diferenciação para o café da região. Inicialmente a APROCAM realizava a cotação e compra conjunta de insumos e auxiliava na comercialização em mercados convencionais, como a busca de cotações ou de negociações da produção de seus associados.

A partir dos anos 2000 , quando a cafeicultura adentra um período de crise de preços, os produtores da região começam a buscar novas estratégias para reduzir a queda de receitas com a atividade. Em contato com uma empresa multinacional fornecedora de insumos, a APROCAM inicia pesquisas sobre mercados de cafés especiais. Nesse sentido, a visita de um especialista da região do Cerrado Mineiro, que participou do processo de obtenção de IG naquela região, evidenciou o grande potencial do café da Mantiqueira e fez uma série de recomendações de ações a serem seguidas para que a Mantiqueira pudesse obter uma IG.

Nesse período, se iniciaram ações para capacitar produtores para a separação e a secagem do café. Estes começam a participar dos primeiros concursos de cafés especiais, obtendo várias premiações e confirmando o grande potencial da região. 
Em 2002, os cafeicultores da Mantiqueira ganharam as três primeiras colocações no concurso Cup of Coffee, seguida de várias outras premiações nos anos seguintes organizados por empresas e entidades internacionais (Illy, BSCA) e pela própria ABIC.

É a partir da APROCAM que se iniciam as ações de forma a buscar uma indicação geográfica para o café da região. Em 2005, o especialista do Cerrado foi contratado para auxiliar nos estudos para a elaboração do processo de pedido da IG para o café da região. Esse esforço foi encampado por diversas entidades públicas e privadas da região, como as cooperativas Cooperativa Regional dos Cafeicultores do Vale do Rio Verde (COCARIVE), a Cooperativa Regional Agropecuária de Santa Rita do Sapucaí (COPERRITA), o Instituto Mineiro de Agropecuária (IMA), a Prefeitura de Carmo de Minas, a EMBRAPA Café, a Universidade Federal de Lavras e o SEBRAE.

Um dos principais desafios estava justamente na identificação dos produtores que poderiam se interessar em participar da iniciativa. Nesse sentido, o IMA, por meio da EMATER, auxiliou na catalogação dos produtores da região que já vinham participando do programa de boas práticas Certifica Minas, desde 2007.

O SEBRAE, com estudos de branding, auxiliou tanto no desenvolvimento do logotipo da IG como nas ações para valorizar a marca no mercado, com a participação em eventos internacionais do setor. A EMBRAPA e alguns pesquisadores da Universidade Federal de Lavras (UFLA) auxiliaram no estudo para o cumprimento de critérios exigidos pelo INPI para a obtenção da IG na modalidade Indicação de Procedência (IP), analisando características e práticas agronômicas características da região, que constituíssem um saber fazer da região.

Assim, em 2007, o processo de obtenção da IG é submetido ao INPI, sendo aprovado em 2011. Entre outros critérios, que serão melhor explicados a seguir, uma condição necessária para que produtores possam utilizar o selo da IG é que estes comercializem sua produção por meio de uma das três cooperativas filiadas: COCARIVE, COOPERRITA e a Cooperativa Agropecuária do Vale do Sapucaí (COOPERVASS).

O conselho gestor da IG Mantiqueira é composto por representantes de cinco entidades: COCARIVE, COOPERRITA, COOPERVASS, Sindicato do Produtores Rurais de Carmo de Minas e Sindicato dos Produtores Rurais de Santa Rita do Sapucaí. Esse conselho é auxiliado por alguns especialistas, como pesquisadores (UFLA e EMBRAPA-CAFÉ), representantes de consumidores e de torrefadoras. As reuniões não seguem nenhuma periodicidade pré-estabelecida, mas são realizadas pelo menos três reuniões anuais visando solucionar questões ligadas à gestão da IG.

O selo da IG só começou a ser conferido aos primeiros produtores em 2015, estando, portanto, em uma fase inicial. Até meados de 2016, 65 produtores obtiveram o selo, dentre os 4000 produtores que comercializam nas cooperativas vinculadas a IG (na região toda seriam 7800 produtores). O número relativamente pequeno se explica, além do período recente, pelo critério de qualidade estabelecido pelo conselho gestor. 


\subsection{Outras certificações disponíveis para cafeicultores da Mantiqueira}

Na região, os produtores utilizam, ainda, outras certificações, como a Rainforest, UTZ, 3As, entre outras certificações privadas. Também, não se pode negligenciar o uso da Certifica Minas, certificação realizada pela EMATER e pelo IMA, que confere aspectos de sustentabilidade da propriedade rural (não é exclusivo para café). Todas essas certificações buscam verificar se as propriedades garantem o cumprimento de diversos critérios socioambientais ou de qualidade do produto.

Dados de Vilella e Rufino (2012) apontam a UTZ e a Certifica Minas como as principais certificações adotadas por cafeicultores do Sul de Minas. De acordo com o extenso levantamento realizado, $17 \%$ dos cafeicultores da região estariam adotando a certificação. Contudo, $72 \%$ desses produtores só buscaram a certificação pública Certifica Minas, o que se justifica pelos menores custos de obtenção e de critérios mais simples de serem cumpridos, se comparada às certificações privadas internacionais. Contudo, segundo os entrevistados da presente pesquisa, o Certifica Minas não é visto como uma certificação que permite acesso aos mercados de nicho com melhor remuneração, especialmente no exterior.

Outro mecanismo de marketing muito utilizado na região é o "direct trade", estratégia na qual o produtor e sua propriedade figuram como marcas do seu café. A presença de uma importante trading na região, a Carmo Coffees, tem permitido que alguns produtores sejam conhecidos por torrefadores de outros países, elevando substancialmente o valor recebido por saca. Nesse sentido, o uso de testes de "bebida”, em que é atribuída uma pontuação de 0 a 100 , se constituem como o principal critério para que o produtor possa comercializar sua produção a preços elevados.

Já a IG, ao contrário dos dois mecanismos mencionados, não faz a verificação in loco nas propriedades ou teste do produto. Apesar de uma série de recomendações serem estabelecidas, não são feitas verificações periódicas. Somente se o conselho gestor solicitar é que as verificações seriam realizadas. Dado que o selo da IG começou a ser conferido efetivamente em 2015 e só foi concedido a 65 produtores, ainda não se observou a necessidade desse procedimento.

Nesse sentido, observa-se uma interação importante entre a IG, as certificações e o "direct trade". O ideal seria que houvesse complementariedade entre esses diferentes mecanismos de transmissão de informação de forma a agregar o maior valor possível ao produto. Contudo, observam-se algumas fricções relatadas por alguns entrevistados, que acreditam que a IG não traria grande vantagem para produtores já conhecidos e que obtém preços elevados pela reconhecida qualidade de seu produto. Nesse sentido, seria difícil atrair os melhores produtores a participar da IG, o que tenderia a baixar o nível de qualidade geral.

Logo, a IG teria um valor maior para produtores menos conhecidos ou que tenham adentrado recentemente na produção de cafés especiais. Assim, a IG tenderia a elevar a qualidade média do café da região, dado que "puxaria" os produtores de menor qualidade para padrões elevados, semelhantes aos outros da região. 
Ainda assim, diversos entrevistados revelam que os produtores de café de melhor qualidade não só participam da iniciativa da IG Mantiqueira, como também têm grande atuação na gestão dessa iniciativa.

\section{Considerações Finais}

O presente artigo se propôs a analisar os elementos que levaram algumas regiões produtoras de café a buscarem mecanismos de diferenciação, as chamadas Indicações Geográficas. As duas experiências analisadas demonstram a importância da organização associativa entre os produtores. O protagonismo das cooperativas e associações para o estabelecimento das IGs e sua gestão levanta questionamentos sobre a apropriação dos benefícios econômicos utilizando a "marca" da região. Nas duas iniciativas analisadas, a certificação só é possível caso o produtor comercialize sua produção junto às cooperativas associadas ao conselho gestor da IG.

A cafeicultura do Cerrado Mineiro, a primeira iniciativa analisada, desenvolveu-se em uma elevada organização social, que permitiu a consolidação da marca Café da Região do Cerrado Mineiro. Trata-se da primeira iniciativa de IG para café no Brasil, demonstrando um protagonismo nesse sentido. Portanto, a busca de uma sinergia territorial, explorando as vantagens comparativas e competitivas desse território, requereu a superação do voluntarismo e do individualismo, constituindo-se em exemplo de experiência local bem-sucedida de associação entre produtores rurais. Suas organizações representativas e arranjos institucionais (estruturas de governanças locais-territoriais) criaram condições adequadas para o sucesso da cafeicultura do cerrado mineiro.

O processo de organização na Mantiqueira ocorreu posteriormente, inclusive influenciado por atores que participaram da iniciativa no Cerrado, e demonstra algumas preocupações em não repetir "erros" da primeira IG. Atores entrevistados revelaram uma preocupação em não formar um território muito vasto, em que a identidade local e mesmo a produção de café não predominassem. Dessa forma, constitui-se uma região menor, com área e número de municípios bem mais reduzido.

Outra preocupação presente no desenho do território da IG Mantiqueira se refere à qualidade do produto que poderá utilizar o selo da IG, em que uma qualidade de bebida mais elevada que a do Cerrado foi estabelecida. Se, por um lado, isso permite uma maior agregação de valor ao café certificado da região, por outro, diversos cafeicultores da região foram excluídos dessa iniciativa, suscitando críticas.

Ao se comparar as duas iniciativas, evidenciam-se alguns elementos comuns que tiveram papel determinante na obtenção da certificação de IG e na sua posterior gestão. Fica clara a relação entre um ambiente organizacional desenvolvido, especialmente nas figuras de associações e cooperativas, que permitiram aglutinar os interesses de parte dos produtores de café, de forma a buscar formas de diferenciação do produto. Não obstante, a participação de entidades externas ao setor, como 
prefeituras e o SEBRAE, também tiveram um papel central nesse processo.

Outro elemento que parece ter grande relevância no sentido de despertar o interesse coletivo dos produtores é, justamente, a capacidade de agregação de valor no produto final. Apesar deste estudo não analisar a real capacidade das IGs em gerar prêmios de preços a produtores, as entrevistas revelam que este é um importante motivador para que os produtores busquem essa forma de certificação por meio de suas associações de representação. Assim, produtos com menor capacidade de diferenciação para a entrada em mercados de nicho apresentam menores incentivos a busca de IG. Nesse caso, é pouco provável que a busca pela IG parta do setor produtivo, sendo necessário um maior incentivo por parte do poder público.

As duas experiências relatadas acima demonstram a importância do processo de organização dos produtores por meio de associações na busca de uma certificação de caráter regional, que permita a agregação de valor no café. Contudo, como discutido na seção dois, a obtenção da IG deveria ir muito além da simples agregação de valor a um produto. Nesse sentido, a constituição de uma IG para um produto ajudaria a aglutinar os atores sociais na busca de uma identidade territorial (NIERDELE, 2014).

Contudo, observa-se que mesmo as iniciativas que partem do setor produtivo enfrentam dificuldades em conduzir a formação de uma identidade territorial. Os dois casos analisados demonstram que a obtenção da IG não significa necessariamente que se construiu uma identidade territorial na região que obteve a certificação. Poderia argumentar-se que a própria organização dos produtores na busca pela certificação seria resultado de uma identidade pré-existente. Ainda assim, em ambos os casos analisados, encontraram-se poucos relatos de como a obtenção da certificação teria gerado uma interação virtuosa entre os atores, no sentido de fortalecer a identidade e permitir o desenvolvimento de outras atividades econômicas nos territórios.

No caso da Mantiqueira, atores entrevistados relatam que apesar do café estar auxiliando na divulgação das belezas naturais e da cultura da região e, portanto, auxiliando na construção de uma de uma identidade territorial, ela ainda é muito incipiente e restrita a cafeicultura. Ainda assim, região já conta com um importante polo turístico sediado nos municípios de São Lourenço e Caxambu, também conhecido como Águas da Mantiqueira de Minas. O slogan desse circuito turístico é "Montanha, Água e Café", em que os turistas além de desfrutar das águas termais, podem fazer tours por fazendas de café na região de Carmo de Minas.

No Cerrado Mineiro, mesmo com a consolidação da IG na modalidade DO, observa-se que a articulação ainda é muito setorial, embora as lideranças locais sinalizem ações de apoio à agricultura familiar e à busca por iniciativas em outros setores, como o turismo. Na prática, o que se destaca é a busca pela defesa e pelo fortalecimento da cadeia produtiva e da ideia guia vinculada ao café, sem considerar outras questões para a promoção do desenvolvimento rural integrado (JESUS, 2013). 
Por fim, vale ressaltar que a interação das diferentes entidades públicas e privadas, na construção de uma identidade territorial que permita um maior desenvolvimento dessa região, ainda é muito tímida quando comparada a outras regiões brasileiras que utilizaram a IG como forma de impulsionar o turismo e outras atividades econômicas. O Vale dos Vinhedos, na serra gaúcha, que obteve uma IG para o vinho lá produzido, é um bom exemplo. Lá, observa-se uma forte interação entre a indústria vinícola, o setor turístico e o comércio, de forma geral. Nesse processo, os atores públicos também atuam de forma relevante visando coordenar o processo de construção e exploração econômica da identidade regional (ORTEGA e JEZIORNY, 2011).

\section{Referencias}

ALCOFORADO, I. G. A construção de mercados certificados - uma abordagem neo institucionalista. In: CONGRESSO BRASILEIRO DE ECONOMIA E SOCIOLOGIA RURAL, 2002, Passo Fundo, RS. Anais... Passo Fundo: SOBER, 2002.

BARRA, G., SILVA, V.; MACHADO, R. O papel das associações de interesse privado no mercado cafeeiro brasileiro. REGE Revista de Gestão, 14(2), 17-31, 2007.

CAÇÃO, C. M. Os anos iniciais da cafeicultura no Sul de Minas: apontamentos da imprensa regional (1870-1890). In: XVIII Encontro Regional da ANPUH. Mariana-MG, 2012.

DUTRA, D. R.; MACHADO, R. T. M.; CASTRO, C. C. Ações públicas e privadas na implantação e desenvolvimento de indicações geográficas do café em Minas Gerais. Informe GEPEC, vol. 13 n ${ }^{\circ} 1$, p.127-148, jan./jun., 2009. Universidade Estadual do Oeste do Paraná - UNIOESTE, Cascavel, Paraná, 2009.

FILETTO, F.; ALENCAR, E. Introdução e expansão do café na região sul de minas gerais. Organizações Rurais e Agroindustriais, 3(1), 1-10, 2001.

HOFF, D. N., JESUS, C. M., ORTEGA, A. C. Denominações de Origem no Brasil e na Espanha: análise de casos selecionados sob a noção de Terroir. In: ORTEGA, A. C. \& ESTRADA, E. M. Desenvolvimento em Territórios Rurais: estudos comparados de Brasil e Espanha.1 ed. Campinas : Alínea, 2015, v.1, p. 151-176.

LEME, P. H. M. V. A Construção do Mercado de Cafés Certificados e Sustentáveis da Utz Certified no Brasil: As Práticas e os Arranjos de Mercado. Tese de doutorado em Administração. Universidade Federal de Lavras (UFLA), 2015. 273 p. 
IBGE - INSTITUTO BRASILEIRO DE GEOGRÁFIA E ESTATÍSTICAS. Produção Agrícola Municipal 2013. Disponível em: www.ibge.gov.br. Acesso: abril-2016.

JESUS, C. M. Desenvolvimento territorial rural: análise comparada entre os territórios constituídos autonomamente e os induzidos pelas políticas públicas no Brasil e na Espanha. 2013. 289 f. tese (Doutorado) - Programa de Pós-Graduação em Ciência Econômica da Universidade Federal de Uberlândia, Uberlândia, 2013.

JESUS, C. M.; PEROSA, B. . EXPORTAÇÃO DE CAFÉ: a experiência da APPCER no Cerrado Mineiro. Agroanalysis (FGV), v. 37, p. 29-30, 2017.

MASCARENHAS, G. Indicações geográficas no Brasil: principais fatores determinantes do seu reconhecimento e desempenho. In: ENCONTRO NACONAL DE ESTUDOS DO CONSUMO, 4, Anais..., Rio de Janeiro: CPDA, 2008.

NIERDELE, P. Desenvolvimento, instituições e mercados agroalimentares: os usos das indicações geográficas. Desenvolvimento Regional em Debate, 4(2), 21-43, 2014.

ORMOND, J. G. P.; PAULA, S. R. L.; FAVERET FILHO, P. S. C. Café:(re) conquista dos mercados. BNDES Setorial, Rio de Janeiro 10, p. 3-55, 1999.

ORTEGA, A. C. Agronegócios e representação de interesses no Brasil. EDUFU. Uberlândia, 2005.

ORTEGA, A. C. Agronegócio e representação de interesses no Brasil. 2. ed. Uberlândia: Edufu - Editora da Universidade Federal de Uberlândia, v. 1, 296p, 2008.

ORTEGA, A. C.; JESUS, C. M. Café e Território. A cafeicultura no Cerrado Mineiro. 1. ed. Campinas: Editora Alínea, v. 1, 246p, 2012.

ORTEGA, A. C.; JEZIORNY, D . Vinho e Território. A experiência do Vale dos Vinhedos. 1. ed. Campinas - SP: Editora Alínea, v. 1, 187p, 2011.

SAES, M. S. M. A desregulamentação do mercado cafeeiro e as perspectivas para o mercado nacional. Revista de Economia e Sociologia Rural (Impresso), Brasília, v. 33, n.3, p. 7-34, 1995.

SAES, M. S. M.; JAYO, M.; SILVEIRA, R. L. F. Caccer: coordenando ações para a valorização do café do cerrado. In: VII Seminário Internacional PENSA de Agribusiness, 1997, Águas de São Pedro-SP. VII Seminário Internacional PENSA de Agribusiness. Águas de São Pedro, 1997. 
SAES, M.S.M.; FARINA, E.M.M.Q. O Agribusiness do Café do Brasil. São Paulo: Editora Miilkbizz, 1999.

SAES, M.S.M. Estratégias de Diferenciação e Apropriação da Quase-Renda na Agricultura. São Paulo: Annablume/ Fapesp, 197 p., 2009.

SOARES, P. B. D. As indicações Geográficas de Procedência e denominações de origem e o Desenvolvimento Territorial no MERCOSUL. III SEMINÁRIO DE PÓS-GRADUAÇÃO EM SOCIOLOGIA - PPGS/UFSCar, 2012.

VILELA, P.; RUFINO, J. Caracterização da cafeicultura de montanha de Minas Gerais. Estudos INAES e FAPEMIG. Cadeias Produtivas. Café (Vol. I), Belo Horizonte, 2010.

Recebido em 30.11.16

Aprovado em 06.09.17 
